Check for updates

Cite this: RSC Adv., 2021, 11, 31511

Received 12th August 2021

Accepted 13th September 2021

DOI: $10.1039 / \mathrm{d} 1 \mathrm{ra06110 \textrm {K }}$

rsc.li/rsc-advances

\section{Ribose conversion with amino acids into pyrraline platform chemicals - expeditious synthesis of diverse pyrrole-fused alkaloid compounds $\uparrow$}

\author{
Soohyeon Cho,,$^{\mathrm{a}}$ Lina Gu,,$^{\mathrm{ab}} \mathrm{Ik}^{\mathrm{k}}$ Joon IN, ${ }^{\mathrm{a}}$ Bo Wu, ${ }^{\mathrm{c}}$ Taehoon Lee, ${ }^{\mathrm{d}}$ Hakwon Kim ${ }^{\mathrm{d}}$ \\ and Sangho Koo (iD *ab
}

One-pot conversion of sustainable D-ribose with L-amino acid, methyl esters produced pyrrole-2carbaldehydes 5 in reasonable yields (32-63\%) under pressurized conditions of $2.5 \mathrm{~atm}$ at $80{ }^{\circ} \mathrm{C}$. The value-added pyrraline compounds 5 as platform chemicals were utilized for quick installation of polyheterocyclic cores for the development of pyrrole-motif natural and artificial therapeutic agents. A pyrrole-fused piperazin-2-one scaffold 6 was prepared by reductive amination of pyrralines 5 with benzylamine. While further cyclization of pyrralines 5 with ethane-1,2-diamine produced pyrrolopiperazin-2-ones 7 with an extra imidazolidine ring, the reaction with 2-amino alcohols derived from natural L-amino acids, alanine, valine, and phenylalanine, respectively provided pyrrolo-piperazin-2-ones 8, 9, and 10 with oxazolidine as the third structural core. Cell viability and an anti-inflammatory effect of the synthesized compounds were briefly tested by the MTT method and the Griess assay, among which $8 \mathrm{~h}$ and $10 \mathrm{~g}$ exhibited significant anti-inflammatory effects with negligible cell toxicity.

\section{Introduction}

Pyrrole is an interesting five-membered heterocyclic compound with the nitrogen lone-pair electrons being delocalized within the ring for aromaticity. It is therefore non-basic contrary to the six-membered ring homologue, pyridine. Alkaloid natural products containing pyrrole as a pharmacophore exhibit various biological activities such as sedative, anti-inflammatory, anti-biotic, anti-cancer, anti-hypertensive, anti-convulsant, antimalarial, and many more. ${ }^{1-6}$ The organic synthesis of pyrrole was reported in the late $19^{\text {th }}$ century,,$^{7-9}$ among which the PaalKnorr method utilizing a 1,4-dicarbonyl compound and primary amine was the first (Fig. 1). ${ }^{\mathbf{1 0}-\mathbf{1 2}}$ The Hantzsch method by the reaction of $\alpha$-haloketone and $\beta$-ketoester with a primary amine is useful for the preparation of 3-carboxylated pyrroles. ${ }^{13,14}$ In

\footnotetext{
${ }^{a}$ Department of Energy Science and Technology, Department of Chemistry, Myongji University, Myongji-Ro 116, Cheoin-Gu, Yongin, Gyeonggi-Do, 17058, Korea. E-mail: sangkoo@mju.ac.kr

${ }^{b}$ School of Pharmacy, East China University of Science and Technology, Meilong Road 130, Shanghai, 200237, China

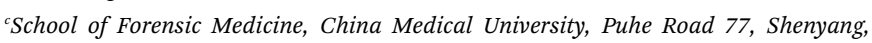
110122, China

${ }^{d}$ Global Center for Pharmaceutical Ingredient Materials, Department of Applied Chemistry, Kyung Hee University, Yongin, Gyeonggi-Do, 17104, Korea

$\dagger$ Electronic supplementary information (ESI) available: Cell viability assays, nitric oxide concentration (Griess assay), picture demonstration for the pressure reaction, and ${ }^{1} \mathrm{H} /{ }^{13} \mathrm{C}$ NMR spectra for compounds $5,6,7,8,9$, and 10 . See DOI: 10.1039/d1ra06110k

\$ These authors contributed equally.
}

1948, Clauson-Kaas reported furan conversion into 2,5-dimethoxytetrahydrofuran for the efficient preparation of pyrroles. ${ }^{15}$ Many others then modified the above original methods for the syntheses of various pyrrole compounds. ${ }^{\mathbf{1 6 - 3 3}}$

Transformation of D-glucose as sustainable biomass into 5hydroxymethyl-2-furfural (5-HMF) as a value-added platform chemical has been well documented in the literature in recent years. ${ }^{34-36}$ Utilization of reducing sugars for the preparation of pyrroles would also be beneficial and providential. In 1912, Maillard reported the reaction between D-glucose and amino acids at high temperature $\left(>140^{\circ}\right)$ to produce hundreds of small chemicals for flavouring in food chemistry, ${ }^{37}$ which was later known to include pyrraline 1, the nitrogen analogue of 5-HMF, in a very small quantity. ${ }^{38}$ Pyrraline 1 would be a useful platform
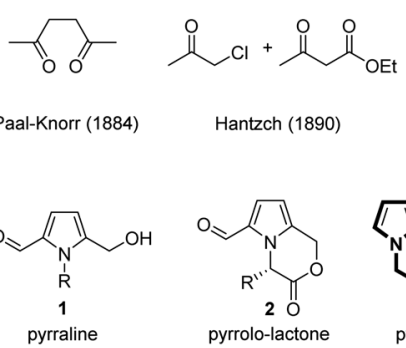

Hantzch (1890)

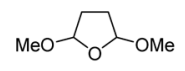

Clauson-Kaas (1948)
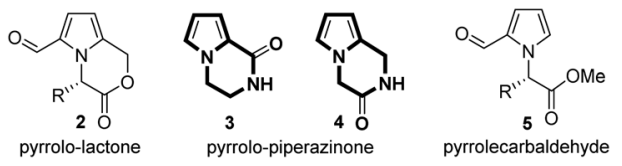

Fig. 1 The original synthetic methods of pyrrole and structures of some pyrrole derivatives. 
chemical for the development of pyrrole-motif natural and artificial therapeutic agents by further reactions. ${ }^{39-43}$

The first chemical synthesis of pyrralines 1 by Kato from the reaction of D-glucose and primary amines either at $100{ }^{\circ} \mathrm{C}$ in $\mathrm{H}_{2} \mathrm{O}$ for $1 \mathrm{~h}$ or at $70^{\circ} \mathrm{C}$ in $\mathrm{MeOH}$ for $3 \mathrm{~h}$ both with acetic acid just confirmed the formation of pyrralines $1 .{ }^{44}$ Monnier reported the synthesis of butyl pyrraline $1(\mathrm{R}=\mathrm{Bu})$ in only $3.4 \%$ yield by the reaction of $\mathrm{D}$-glucose and butylamine in aqueous acetic acid at $100{ }^{\circ} \mathrm{C}$ for $2 \mathrm{~h}^{38}$ We believed that the low yield of pyrraline 1 was ascribed to the unstable imine intermediates under the aqueous acidic condition. We recently studied the reaction conditions of D-glucose and primary amines, and significantly improved the yield of pyrralines $1(20-50 \%)$ under non-aqueous condition by use of oxalic acid in DMSO at $90{ }^{\circ} \mathrm{C}$ for $30 \mathrm{~min} .{ }^{45}$ Anti-inflammatory and pain-relieving pyrrolo-lactones 2 , which could be isolated from Celastrus orbiculatus $(\mathrm{R}=\mathrm{Bn})$ and Capparis spinosa $(\mathrm{R}=\mathrm{Me})$, were synthesized in $27 \%$ and $32 \%$ yields, respectively when methyl esters of amino acids, phenylalanine and alanine, were used as primary amines in the above one-pot reaction condition. ${ }^{45}$ Nonetheless, it was still necessary to improve the one-pot reaction conditions of sugars and amino acids for reasonable yields of the pyrrole platform chemicals, which might be realized by reducing the formation of tar byproduct under a pressurized reaction condition.

Piperazin-2-one is a privileged structural unit in drug discovery because many of the biologically active natural products and the approved drug molecules contain the above scaffold, ${ }^{46-49}$ which exhibit opiate, ${ }^{50}$ antiviral, ${ }^{51}$ anti-cancer, ${ }^{52}$ and anti-diabetes activities $^{53}$ as well as treatment effects for immunological disorder ${ }^{54}$ and non-Hodgkin's lymphoma. ${ }^{55}$ Pyrrole-fused piperazin-2-ones ( 3 and 4 in Fig. 1) would thus be a very promising structural unit for the discovery of new therapeutic agents. In fact, the structure of pyrrolo-piperazinone 3 has been found in numerous antibiotic and cytotoxic alkaloid natural products, such as agelastatins, ${ }^{56,57}$ longamide ${ }^{58}$ hanishin, ${ }^{59}$ and agesamides. ${ }^{60}$

We envisioned that the structure of pyrrolo-piperazinone 4 would be obtainable from pyrrole-2-carbaldehyde $\mathbf{5}$, which might be prepared by the one-pot "Maillard-type" reaction between Dribose and $\alpha$-amino acids. Amination of the formyl group and subsequent lactam formation with the carboxylic ester in pyrrole-2carbaldehyde 5 would form the core structure of pyrrolopiperazinone 4. In this paper, we described one-pot conversion of D-ribose with various $\alpha$-amino acids under a pressurized condition to obtain reasonable yields of pyrrole-2-carbaldehydes $\mathbf{5}$ as platform chemicals and their further cyclization reactions to pyrrolo-piperazinone derivatives 6-10 as new potential therapeutic agents. Finally, cell viability and anti-inflammatory effect of the synthesized pyrrolo-piperazinones were briefly tested for RAW264.7 cells by the MTT method and the Griess assay.

\section{Results and discussion}

\section{One-pot ribose conversion with amino acid}

D-Ribose was first reacted with L-valine methyl ester in DMSO with oxalic acid at $90^{\circ} \mathrm{C}$ for $30 \mathrm{~min}$ to produce pyrraline $5(\mathrm{R}=\mathrm{i}$ $\mathrm{Pr}$ ) in $24 \%$ yield, which was the previous optimized condition for D-glucose. ${ }^{45}$ Unlike D-glucose case providing pyrrololactones,

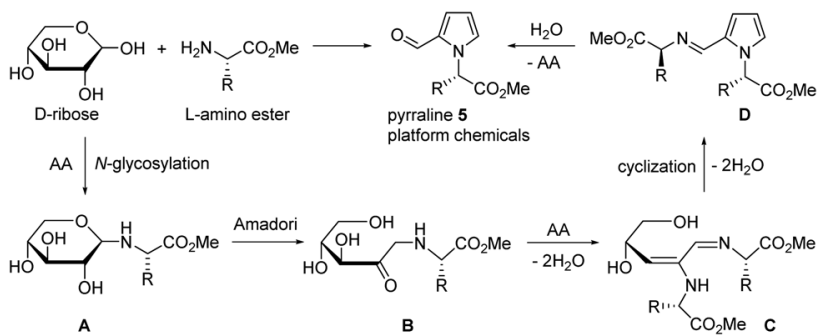

Scheme 1 Ribose conversion with amino ester through $N$-glycosylation, Amadori reaction, and cyclization to produce pyrraline 5 as platform chemicals.

pyrrole-2-carbaldehyde 5 with intact methyl ester was obtained. Pyrroles as the glycosylation end products were believed to be formed through 3-deoxyglucosone intermediate after $\mathrm{N}$-glycosylation and Amadori reaction. ${ }^{38,61,62}$ The reaction of D-ribose was thus speculated to follow $N$-glycosylation (A) and Amadori reaction (B) in sequence (Scheme 1). Second amino ester was introduced to give the structure $\mathbf{C}$ by imine tautomerization and dehydration, which is the adduct of amino esters to the 3-deoxyglucosone homologue from $\mathrm{D}$ ribose. Cyclization of enamine and dehydration produced pyrrole ring D. Finally, hydrolysis of the imine provided pyrraline $\mathbf{5}$ and regenerated amino ester. D-Ribose reaction with other amino esters from L-phenylalanine and L-methionine also produced the corresponding pyrralines 5 in $37 \%(\mathrm{R}=\mathrm{Bn})$ and $30 \%\left(\mathrm{R}=\mathrm{CH}_{2} \mathrm{CH}_{2} \mathrm{SMe}\right)$ yields, respectively, but it was imperative to improve the ribose conversion reaction to utilize pyrralines $\mathbf{5}$ as sustainable platform chemicals for the discovery of potent therapeutic agents.

The ribose conversion reaction with $\alpha$-amino methyl esters under the above condition produced pyrralines 5 in $24-37 \%$ yields as the only isolable product together with dark-brown tarry materials, which suggested that reducing the amount of tar would improve the yield of pyrralines $\mathbf{5}$. The ribose conversion was thus studied for the above three amino esters under pressurized conditions $(1-4 \mathrm{~atm})$ at $90{ }^{\circ} \mathrm{C}$ to reduce the tar formation (Table 1). We found gradual yield improvements of 5 as pressure was increased with the maximum value at $2.5 \mathrm{~atm}$. The yield of 5 was maintained or slowly fell after $3.0 \mathrm{~atm}$.

Table 1 Optimization of D-ribose conversion (\%yield of 5) with Lamino acid, methyl ester at $90{ }^{\circ} \mathrm{C}$ under various pressure conditions
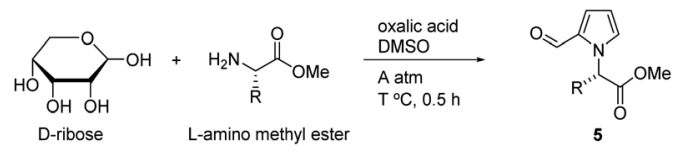

Yield of 5 (\%) under each pressure (atm)

\begin{tabular}{llllllll}
$\mathrm{AA}^{a}$ & 1 & 1.5 & 2 & 2.5 & 3 & 3.5 & 4 \\
\hline Val & $\mathbf{2 4}$ & 29 & 30 & $\mathbf{3 8}$ & 36 & 36 & 33 \\
Phe & $\mathbf{3 7}$ & 38 & 39 & $\mathbf{4 8}$ & 47 & 46 & 46 \\
Met & $\mathbf{3 0}$ & 35 & 36 & $\mathbf{4 2}$ & 37 & 37 & 37
\end{tabular}

${ }^{a}$ Amino acid: valine $(\mathrm{R}=\mathrm{i}-\mathrm{Pr})$, phenylalanine $(\mathrm{R}=\mathrm{Bn})$, methionine $(\mathrm{R}=$ $\mathrm{CH}_{2} \mathrm{CH}_{2} \mathrm{SMe}$ ). 
Table 2 Optimization of D-ribose conversion (\% yield of 5) with Lamino acid, methyl ester at 2.5 atm under various temperature conditions

\begin{tabular}{lllllll}
\hline & \multicolumn{7}{l}{ Yield of $\mathbf{5}(\%)$ at each temperature $\left({ }^{\circ} \mathrm{C}\right)$} \\
\cline { 2 - 7 } $\mathrm{AA}^{a}$ & 60 & 70 & 75 & 80 & 85 & 90 \\
\hline Val & 29 & 31 & 38 & $\mathbf{4 2}$ & 39 & 38 \\
Phe & 35 & 41 & 45 & $\mathbf{5 4}$ & 48 & 48 \\
Met & 32 & 35 & 37 & $\mathbf{4 6}$ & 43 & 42
\end{tabular}

${ }^{a}$ Amino acid: valine $(\mathrm{R}=\mathrm{i}-\mathrm{Pr})$, phenylalanine $(\mathrm{R}=\mathrm{Bn})$, methionine $(\mathrm{R}=$ $\left.\mathrm{CH}_{2} \mathrm{CH}_{2} \mathrm{SMe}\right)$.

Reaction temperature was then screened from $60{ }^{\circ} \mathrm{C}$ to $90{ }^{\circ} \mathrm{C}$ at the optimal pressure of $2.5 \mathrm{~atm}$ (Table 2). The yield of 5 was progressively improved as temperature was raised up to $80{ }^{\circ} \mathrm{C}$ and fell slowly down since then. The best yields of pyrralines 5 were obtained at $80{ }^{\circ} \mathrm{C}$ (2.5 atm) for all three amino esters, which were approximately $150 \%$ of those at the previous optimal condition for glucose $\left(90{ }^{\circ} \mathrm{C}, 1 \mathrm{~atm}\right) .{ }^{45}$

Generality of the ribose conversion with $\alpha$-amino methyl esters and improvement of the yields of pyrralines $\mathbf{5}$ under the pressure condition $\left(2.5 \mathrm{~atm}, 80^{\circ} \mathrm{C}\right)$ compared to the original one $\left(1 \mathrm{~atm}, 90^{\circ} \mathrm{C}\right)$ were summarized in Table 3 , in which 150 $300 \%$ yield increases for pyrralines 5 were notified for eleven natural $L$ - $\alpha$-amino acids. Amino esters reacted with D-ribose as nucleophile and the yields of pyrralines 1 were reflected by the nucleophilicity of each amino ester, which was differentiated by the $\alpha$-substituent $\mathrm{R}$ in this case. It was initially predicted that $\mathrm{R}$ would provide steric hinderance to the amino group, thereby lower yield of 1 could be obtained as the size of $\mathrm{R}$ was increased. Surprisingly, it was L-glycine $(\mathrm{R}=\mathrm{H})$, however, which gave the lowest yield $(32 \%)$ of pyrraline $\mathbf{1}$, and the highest yield of $\mathbf{1}$ $(63 \%)$ was obtained for $\mathrm{L}-$-leucine $(\mathrm{R}=\mathrm{i}-\mathrm{Bu})$.

Table 3 Improvement of D-ribose conversion (\% yield of 5 ) with Lamino acid, methyl ester at $2.5 \mathrm{~atm}$ and $80^{\circ} \mathrm{C}$ compared at $1.0 \mathrm{~atm}$ and $90{ }^{\circ} \mathrm{C}$

\begin{tabular}{llll}
\hline & & \multicolumn{2}{l}{ Yield of $\mathbf{5}(\%)$} \\
\cline { 3 - 4 } & & & \\
Amino Acid $^{a}$ & Compound 5 & 1.0 atm, $90{ }^{\circ} \mathrm{C}$ & 2.5 atm, $80{ }^{\circ} \mathrm{C}$ \\
\hline Gly & $\mathbf{5 a}$ & 10 & 32 \\
Ala & $\mathbf{5 b}$ & 23 & 38 \\
Val & $\mathbf{5 c}$ & 24 & 42 \\
Leu & $\mathbf{5 d}$ & 43 & 63 \\
Ile & $\mathbf{5 e}$ & 20 & 40 \\
Phe & $\mathbf{5 f}$ & 37 & 54 \\
Bn & $\mathbf{5 g}$ & 20 & 53 \\
Asp & $\mathbf{5 h}$ & 18 & 47 \\
Glu & $\mathbf{5 i}$ & 16 & 46 \\
Met & $\mathbf{5 j}$ & 30 & 55 \\
Trp & $\mathbf{5 k}$ & 34 &
\end{tabular}

${ }^{a}$ Amino acid (R): glycine (H), alanine (Me), valine (i-Pr), leucine (i-Bu), isoleucine $(s-\mathrm{Bu})$, phenylalanine $\left(\mathrm{CH}_{2} \mathrm{Ph}\right)$, benzylalanine $\left(\mathrm{CH}_{2} \mathrm{CH}_{2} \mathrm{Ph}\right)$, aspartic acid $\left(\mathrm{CH}_{2} \mathrm{CO}_{2} \mathrm{Me}\right)$, glutamic acid $\left(\mathrm{CH}_{2} \mathrm{CH}_{2} \mathrm{CO}_{2} \mathrm{Me}\right)$, methionine $\left(\mathrm{CH}_{2} \mathrm{CH}_{2} \mathrm{SMe}\right)$, tryptophane (3-indole).

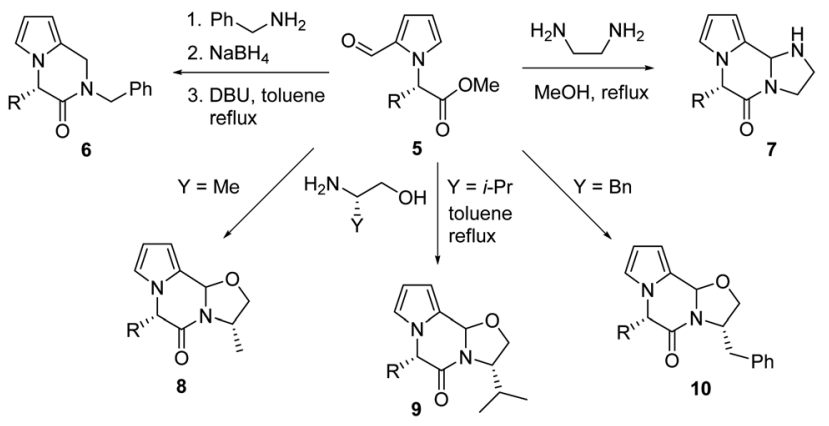

Scheme 2 Further cyclization of pyrraline platform chemicals 5 to pyrrolo-piperazin-2-one derivatives 6-10.

It seemed that the hydrogen bonding between primary amino and ester groups would reduce the nucleophilicity of amino esters. L-Glycine with no $\alpha$-substituent may participate in the hydrogen bonding, which reduces the nucleophilicity of the amino group. Primary alkyl or aryl substituents R (e.g., Leu, Phe, $\mathrm{Bn})$ would be good enough to maintain the nucleophilicity of amino group by interrupting the hydrogen bonding without providing steric hinderance to the amino group. Pyrralines 5 can now be obtained in $32-60 \%$ yield by one-pot conversion from D-ribose with L-amino acid methyl esters and certainly be flatform chemicals for the syntheses of pyrrole-based poly heterocyclic compounds as potential therapeutic agents.

\section{Cyclization of the platform pyrralines 5 to pyrrolo- piperazinones 6-10}

We demonstrated three different methods for further cyclization of pyrralines $\mathbf{5}$, derived from eight different L-amino acids glycine (a), alanine (b), valine (c), isoleucine (d), phenylalanine (e), benzylalanine (f), aspartic acid (g), and methionine (h) with five different nitrogen reagents to produce the 2-piperazin2-one skeleton as the second pharmacophore with the basic pyrrole scaffold (Scheme 2 and Table 4). The 1,5-relationship between the carbonyl carbons of formyl and ester groups in pyrralines 5 allowed $\delta$-lactam formation with primary amines by reductive amination and cyclization. Benzylamine was utilized for the reductive amination with pyrralines 5 , which was carefully carried out first by imine formation in $\mathrm{MeOH}$ at $25{ }^{\circ} \mathrm{C}$, followed by selective $\mathrm{NaBH}_{4}$ reduction at $0{ }^{\circ} \mathrm{C}$ due to the presence of the sensitive $\alpha$-amino ester group. The resulting secondary amine underwent lactam formation with the ester group in the presence

Table 4 Yields (\%) of the reactions in Scheme 2

\begin{tabular}{lllllll}
\hline Entry & $\mathrm{R}$ & $\mathbf{6}$ & $\mathbf{7}$ & $\mathbf{8}$ & $\mathbf{9}$ & $\mathbf{1 0}$ \\
\hline $\mathbf{a}$ & $\mathrm{H}$ & 36 & 58 & 12 & 4 & 6 \\
$\mathbf{b}$ & $\mathrm{Me}$ & 66 & 87 & 41 & 27 & 32 \\
$\mathbf{c}$ & $\mathrm{i}-\mathrm{Pr}$ & 73 & 94 & 73 & 61 & 41 \\
$\mathbf{d}$ & $s-\mathrm{Bu}$ & 86 & 91 & 77 & 50 & 31 \\
e & $\mathrm{PhCH}_{2}$ & 41 & 86 & 52 & 71 & 62 \\
$\mathbf{f}$ & $\mathrm{PhCH}_{2} \mathrm{CH}_{2}$ & 64 & 88 & 22 & 51 & 57 \\
$\mathbf{g}$ & $\mathrm{MeO}_{2} \mathrm{CCH}_{2}$ & 84 & 72 & 27 & 10 & 14 \\
$\mathbf{h}$ & $\mathrm{MeSCH}_{2} \mathrm{CH}_{2}$ & 47 & 87 & 24 & 24 & 22
\end{tabular}


of DBU at the reflux temperature of toluene to produce pyrrolopiperazin-2-ones 6 in 36-84\% yields (Table 4).

$\alpha, \omega$-Alkanediamine (e.g., 1,2-ethanediamine) can be utilized in lactam formation with pyrralines $\mathbf{5}$, where initially formed imine may react with the second amine by cyclization. ${ }^{\mathbf{4 0 1}}$ One of the resulting two symmetrical secondary amines participated in further cyclization with the ester group to form pyrrolopiperazinones 7 with an imidazolidine ring as the third core in $58-94 \%$ yields (Table 4 ). The conversion of pyrralines 5 with norephedrine was reported, ${ }^{\mathbf{4 2}}$ where the initially formed imine was reacted with the alcohol group by cyclization to form an oxazolidine unit, which underwent further cyclization with the ester group to produce pyrrolo-piperazinones with the oxazolidine unit. In a similar manner, 2-amino alcohols derived from natural $\alpha$-amino acids, alanine $(\mathrm{Y}=\mathrm{Me})$, valine $(\mathrm{i}-\mathrm{Pr})$, and phenylalanine $(\mathrm{Bn})$, can be utilized for the syntheses of oxazolidine-fused pyrrolo-piperazinones 8, 9, and 10, respectively. Even though somewhat lower yields were notified for the pyrralines 5 from Gly $(\mathbf{a}, \mathrm{R}=\mathrm{H})$, Asp $\left(\mathrm{g}, \mathrm{CH}_{2} \mathrm{CO}_{2} \mathrm{CH}_{3}\right)$, and Met (h, $\mathrm{CH}_{2} \mathrm{CH}_{2} \mathrm{SCH}_{3}$ ), fare yields of poly heterocyclic products 8-10 were obtained for the pyrralines $\mathbf{5}$ derived from $\alpha$-amino acids with a simple alkyl substituent (Table 4).

\section{Cell viability (MTT test) and anti-inflammation assays (Griess method)}

All the synthesized pyrrolo-piperazinones 6-10 (a-h) were briefly screened for cytotoxicity to RAW264.7 cells (Murine macrophages) at a fixed concentration at $20 \mu \mathrm{g} \mathrm{mL}{ }^{-1}$. Four compounds $\mathbf{7 a}, \mathbf{7 c}, \mathbf{8 h}$, and $\mathbf{1 0 g}$ showed $80 \%$ or higher cell viability by Formazan formation in MTT $\{3-(4,5-d i m e t n y t h i a z o l-$ 2-yl)-2,5-diphenyl-thetazolium bromide $\}$ assay (see ESI $\dagger$ ). ${ }^{63}$ The other regents might still be good candidates for antibiotics.

Anti-inflammatory activities to RAW264.7 cells were then tested for the above four samples at five different concentrations $\left(0,1,5,10,20 \mu \mathrm{g} \mathrm{mL} \mathrm{m}^{-1}\right.$ each) in $24 \mathrm{~h}$ after triggering by 1 $\mu \mathrm{g} \mathrm{mL}^{-1}$ of LPS (lipopolysaccharides). Nitric oxide concentration, which is correlated with the inflammation level, was determined by the Griess method. ${ }^{64}$ The measurements were repeated three times. The mean and standard deviation values

Table 5 Nitric oxide concentration ( $\mu$ M) by Griess assay for RAW264.7 cells after treatment of each reagent $\left(\mu \mathrm{g} \mathrm{mL}^{-1}\right)$ and lipopolysaccharides (LPS, $1 \mu \mathrm{g} \mathrm{mL}^{-1}$ )

\begin{tabular}{|c|c|c|c|c|}
\hline $\begin{array}{l}\text { Conc. } \\
\left(\mu \mathrm{g} \mathrm{mL}^{-1}\right)\end{array}$ & $7 a$ & 7c & $8 \mathrm{~h}$ & $10 \mathrm{~g}$ \\
\hline $0^{a}$ & $3.21 \pm 0.15$ & $3.21 \pm 0.15$ & $3.21 \pm 0.15$ & $3.21 \pm 0.15$ \\
\hline 0 & $25.54 \pm 2.60$ & $25.54 \pm 2.60$ & $25.54 \pm 2.60$ & $25.54 \pm 2.60$ \\
\hline 1 & $26.23 \pm 2.60$ & $25.03 \pm 2.13$ & $22.23 \pm 2.13$ & $17.31 \pm 1.31$ \\
\hline 5 & $22.31 \pm 1.65$ & $24.32 \pm 1.31$ & $21.32 \pm 1.31$ & $15.32 \pm 2.60$ \\
\hline 10 & $20.30 \pm 2.65$ & $23.51 \pm 1.10$ & $16.31 \pm 1.10$ & $14.31 \pm 2.11$ \\
\hline 20 & $20.02 \pm 3.64$ & $21.65 \pm 2.51$ & $14.32 \pm 2.51$ & $11.10 \pm 1.31$ \\
\hline
\end{tabular}

${ }^{a}$ Without LPS treatment. of the NO concentration $\left(\mu \mathrm{g} \mathrm{mL}^{-1}\right)$ for the cell treated by each compound at each concentration are listed in Table 5. Pyrrolopiperazinones $\mathbf{8 h}$ and $\mathbf{1 0 g}$ containing oxazolidine as the third core exhibited significant anti-inflammation activities, in which $\mathrm{IC}_{50}$ values were estimated to be $20 \mu \mathrm{g} \mathrm{mL} \mathrm{m}^{-1}$ and $10 \mu \mathrm{g} \mathrm{mL}^{-1}$, respectively. For comparison, $\mathrm{IC}_{50}$ of NIL $\left\{\mathrm{L}-N^{6}-(1\right.$-iminoethyl) lysine $\}$ as a positive control was measured as $10.17 \mathrm{mM}$, which is converted as $2.64 \mu \mathrm{g} \mathrm{mL}{ }^{-1}$ (see $\mathrm{ESI} \dagger$ ).

\section{Experimental}

\section{General experimental}

Reactions were performed in a well-dried flask under argon atmosphere unless noted otherwise. A mini-clave steel reactor (100 mL, up to 15 bar) made from büchiglasuster (Switzerland) was used for the pressurized reactions. The pressure was controlled by argon gas (see ESI $\dagger$ for picture demonstration). Solvents used as reaction media were dried over pre-dried molecular sieve ( 4 A ) by microwave oven. Solvents for extraction and chromatography were reagent grade and used as received. The flash column chromatography was performed by the method of Still (J. Org. Chem., 1978, 43, 2923) with silica gel 60 (70-230 mesh) using a mixture of EtOAc/hexane as gradient eluent. ${ }^{1} \mathrm{H}$ and ${ }^{13} \mathrm{C}$ NMR spectra were respectively recorded on a $400 \mathrm{MHz}$ and $100 \mathrm{MHz}$ NMR spectrometer in deuterated chloroform $\left(\mathrm{CDCl}_{3}\right)$ with tetramethylsilane (TMS) as an internal reference unless noted otherwise.

\section{Cell viability assay (MTT method) ${ }^{63}$}

RAW264.7 cells (Murine macrophages) were cultured using Dulbecco's modified Eagle medium (DMEM) (Welgene, Seoul, Korea) containing 10\% fetal bovine serum (FBS), $2 \mathrm{mM}$ glutamine, and 100 unit/mL of antibiotics (Gibco BRL, Rockville, $\mathrm{MD})$. Cells were incubated at $37{ }^{\circ} \mathrm{C}$ incubators, which maintained a humidified atmosphere of $5 \%(\mathrm{v} / \mathrm{v}) \mathrm{air} / \mathrm{CO}_{2}$. The incubated RAW264.7 cells $\left(5 \times 10^{3} /\right.$ well $)$ were seeded to a 96-cell culture plate to conduct a cell viability assay. The RAW264.7 cells prepared for the viability assay went through $18 \mathrm{~h}$ of attachment and stabilization. The growth medium was removed and replaced by a fresh medium without FBS. The synthetic compounds were treated to the cells at a concentration of 20 $\mu \mathrm{g} \mathrm{mL} \mathrm{L}^{-1}$ and the resulting cells were incubated for $24 \mathrm{~h}$. The sample-treated culture medium was removed and $100 \mu \mathrm{g} \mathrm{mL} \mathrm{m}^{-1}$ of 3-(4,5-dimetnythiazol-2-yl)-2,5-diphenyl-thetazolium bromide (MTT) was added to each well. In $1 \mathrm{~h}$, purple formazan produced by cellular respiration was dissolved in a $200 \mu \mathrm{L}$ DMSO solution and the absorbance at $560 \mathrm{~nm}$ was measured using a multi-plate reader. The analyses were repeated three times. The results were expressed as means of three independent experiments.

\section{Measurement of nitric oxide concentration (Griess assay) ${ }^{64}$}

RAW264.7 cells were transferred into $3 \times 10^{5}$ cells per well in a 96-cell culture plate and incubated for $24 \mathrm{~h}$ in a $5 \% \mathrm{CO}_{2}$ incubator at $37^{\circ} \mathrm{C}$. Four different concentrations $(1,5,10$, and $20 \mu \mathrm{g} \mathrm{mL}^{-1}$ ) of synthetic compounds was treated to the incubated RAW264.7 cells. Simultaneously, $1 \mu \mathrm{g} \mathrm{mL}^{-1}$ of 
lipopolysaccharides (LPS) (Sigma-Aldrich, St. Louis, MO) was added and the resulting cells were incubated for $24 \mathrm{~h}$. The same amount of Griess reagent (Sigma-Aldrich) equal to $100 \mu \mathrm{L}$ of the culture solution was added according to the manufacturer's recommendations, and the absorbance was measured at $540 \mathrm{~nm}$ with a multi-plate reader. The NO concentration in the culture medium was determined using a standard curve for each concentration of sodium nitrite.

General procedure for D-ribose conversion with L-amino acids for the synthesis of pyrraline 5

Methyl 2-(2-formyl-1H-pyrrol-1-yl)acetate (5a). To a stirred solution of glycine (10.0 g, $0.133 \mathrm{~mol}, 1$ equiv.) in $\mathrm{MeOH}(7 \mathrm{~mL})$ at $0{ }^{\circ} \mathrm{C}$ under argon atmosphere was slowly added thionyl chloride ( $9.73 \mathrm{~mL}, 0.133 \mathrm{~mol}, 1$ equiv.) through a syringe. The mixture was then heated at $65{ }^{\circ} \mathrm{C}$ for $8 \mathrm{~h}$ and cooled to room temperature. The mixture was triturated with $\mathrm{Et}_{2} \mathrm{O}$ to give glycine methyl ester, ammonium chloride salt as white crystalline salt (16.57 g, $0.133 \mathrm{~mol})$.

Under ambient pressure. To a stirred solution of the above glycine methyl ester, ammonium chloride salt (8.35 g, $66.5 \mathrm{mmol}, 1$ equiv.) in DMSO $(20 \mathrm{~mL})$ were added $\mathrm{Et}_{3} \mathrm{~N}(18.4$ $\mathrm{mL}, 0.133$ mol, 2 equiv.) and D-ribose (10.0 g, $66.6 \mathrm{mmol}, 1$ equiv.). After complete dissolution, oxalic acid $(12.0 \mathrm{~g}$, 0.133 mol, 2 equiv.) was added and the resulting mixture was heated at $90{ }^{\circ} \mathrm{C}$ for $30 \mathrm{~min}$. Upon cooling to room temperature, the mixture was filtered through a short pad of $\mathrm{SiO}_{2}$ with EtOAc rinsing. The filtrate was concentrated and purified by $\mathrm{SiO}_{2}$ flash column chromatography to give $5 \mathbf{a}(1.08 \mathrm{~g}, 6.45 \mathrm{mmol})$ in $10 \%$ yield as light-yellow liquid.

Under pressure bottle at 2.5 bar. A mixture of glycine methyl ester, ammonium chloride salt (2.00 g, $15.9 \mathrm{mmol})$ and $\mathrm{Et}_{3} \mathrm{~N}$ $(2.18 \mathrm{~mL}, 15.9 \mathrm{mmol})$ in dry DMSO $(10 \mathrm{~mL})$ was stirred in a mini-clave steel reactor and then D-ribose $(4.73 \mathrm{~g}, 31.8 \mathrm{mmol})$ and oxalic acid $(1.41 \mathrm{~g}, 15.9 \mathrm{mmol})$ were added. The mixture was pressurized to 2.5 bar with argon and heated at $80{ }^{\circ} \mathrm{C}$ for $0.5 \mathrm{~h}$. The mixture was then cooled to room temperature and depressurized. The resulting viscous mixture was filtered through a short pad of $\mathrm{SiO}_{2}$ rinsing with EtOAc. The filtrate was concentrated and purified by $\mathrm{SiO}_{2}$ flash column chromatography (eluent $7: 1 \mathrm{EtOAc} /$ hexane) to give 5a (0.85 g, $5.09 \mathrm{mmol})$ in $32 \%$ yield as light-yellow liquid.

Data for $5 \boldsymbol{a} . R_{\mathrm{f}}=0.50$ (4: 6 EtOAc/hexane); ${ }^{1} \mathrm{H}$ NMR $\delta=3.77$ $(\mathrm{s}, 3 \mathrm{H}), 5.08(\mathrm{~s}, 2 \mathrm{H}), 6.31(\mathrm{dd}, J=2.4,1.6 \mathrm{~Hz}, 1 \mathrm{H}), 6.92(\mathrm{dd}, J=$ 4.0, $2.4 \mathrm{~Hz}, 1 \mathrm{H}), 7.00$ (dd, $J=4.0,1.6 \mathrm{~Hz}, 1 \mathrm{H}), 9.54$ (s, 1H) ppm; ${ }^{13} \mathrm{C}$ NMR $\delta=50.0,52.5,110.2,124.6,124.6,132.0,168.7$, 179.8 ppm; IR $\nu=3111,2941,2904,2840,1740,1650,1528$, 1480, 1403, 1359, 1321, 1216, 1081, 1031, 999, $761 \mathrm{~cm}^{-1}$; HRMS (EI) calcd for $\mathrm{C}_{8} \mathrm{H}_{9} \mathrm{NO}_{3}$ 167.0582, found 167.0582.

Methyl ( $S$ )-2-(2-formyl-1H-pyrrol-1-yl)propanoate (5b). The mixture of L-alanine methyl ester, ammonium chloride salt $(2.00 \mathrm{~g}, 14.3 \mathrm{mmol}), \mathrm{Et}_{3} \mathrm{~N}(2.0 \mathrm{~mL}, 14.3 \mathrm{mmol})$, D-ribose (4.35 g, $28.6 \mathrm{mmol})$, and oxalic acid $(1.27 \mathrm{~g}, 14.3 \mathrm{mmol})$ in dry DMSO (10 $\mathrm{mL}$ ) was pressurized to 2.5 bar by argon and reacted at $80{ }^{\circ} \mathrm{C}$ for $30 \mathrm{~min}$ to give $\mathbf{5 b}$ (985 $\mathrm{mg}, 5.4 \mathrm{mmol}$ ) in $38 \%$ yield as light- brown liquid after purification by $\mathrm{SiO}_{2}$ column chromatography.

Data for $5 \boldsymbol{b} . R_{\mathrm{f}}=0.53$ (4:6 EtOAc/hexane); ${ }^{1} \mathrm{H}$ NMR $\delta=1.73$ $(\mathrm{d}, J=7.6 \mathrm{~Hz}, 3 \mathrm{H}), 3.71(\mathrm{~s}, 3 \mathrm{H}), 5.86(\mathrm{q}, J=7.6 \mathrm{~Hz}, 1 \mathrm{H}), 6.30$ (dd, $J=4.0,2.0 \mathrm{~Hz}, 1 \mathrm{H}), 6.98(\mathrm{dd}, J=4.0,1.6 \mathrm{~Hz}, 1 \mathrm{H}), 7.18$ (ddd, $J=$ 2.0, 1.6, $1.2 \mathrm{~Hz}, 1 \mathrm{H}), 9.50(\mathrm{~d}, J=1.2 \mathrm{~Hz}, 1 \mathrm{H}) \mathrm{ppm} ;{ }^{13} \mathrm{C} \mathrm{NMR} \delta=$ 17.6, 52.2, 55.1, 110.0, 125.1, 128.7, 131.3, 171.2, 179.3 ppm; IR $\nu$ = 3116, 2999, 2954, 2851, 2809, 1729, 1608, 1517, 1470, 1406, 1364, 1339, 1313, 1211, 1090, 1066, 1033, 983, $743 \mathrm{~cm}^{-1}$; HRMS (ESI) calcd for $\mathrm{C}_{9} \mathrm{H}_{11} \mathrm{NO}_{3}+\mathrm{Na} 204.0631$, found 204.0636.

Methyl (S)-2-(2-formyl-1H-pyrrol-1-yl)-3-methylbutanoate (5c). The mixture of L-valine methyl ester, ammonium chloride salt ( $2.00 \mathrm{~g}, 11.9 \mathrm{mmol}), \mathrm{Et}_{3} \mathrm{~N}(1.7 \mathrm{~mL}, 11.9 \mathrm{mmol})$, D-ribose $(3.59 \mathrm{~g}, 23.8 \mathrm{mmol})$, and oxalic acid $(1.07 \mathrm{~g}, 11.9 \mathrm{mmol})$ in dry DMSO $(10 \mathrm{~mL})$ was pressurized to 2.5 bar by argon and reacted at $80{ }^{\circ} \mathrm{C}$ for $30 \mathrm{~min}$ to give $5 \mathrm{c}(1.05 \mathrm{~g}, 5.0 \mathrm{mmol})$ in $42 \%$ yield as light-brown liquid after purification by $\mathrm{SiO}_{2}$ column chromatography.

Data for $5 c . R_{\mathrm{f}}=0.76$ (4: 6 EtOAc/hexane); ${ }^{1} \mathrm{H}$ NMR $\delta=0.78$ $(\mathrm{d}, J=6.4 \mathrm{~Hz}, 3 \mathrm{H}), 1.01(\mathrm{~d}, J=6.4 \mathrm{~Hz}, 3 \mathrm{H}), 2.40(\mathrm{~m}, 1 \mathrm{H}), 3.75(\mathrm{~s}$, $3 \mathrm{H}), 5.99(\mathrm{~d}, J=10.4 \mathrm{~Hz}, 1 \mathrm{H}), 6.31$ (ddd, $J=4.0,2.8,1.2 \mathrm{~Hz}, 1 \mathrm{H})$, $6.93(\mathrm{ddd}, J=4.0,1.6,1.6 \mathrm{~Hz}, 1 \mathrm{H}), 7.39$ (ddd, $J=2.8,1.6,1.2 \mathrm{~Hz}$, $1 \mathrm{H}), 9.54(\mathrm{dd}, J=1.6,1.2 \mathrm{~Hz}, 1 \mathrm{H}) \mathrm{ppm} ;{ }^{13} \mathrm{C} \mathrm{NMR} \delta=18.5,19.2$, 33.0, 52.2, 63.8, 110.7, 125.3, 129.9, 131.9, 171.2, 179.9 ppm; IR $\nu$ $=3126$, 2952, 2874, 2846, 2813, 1729, 1655, 1523, 1460, 1408, 1373, 1338, 1258, 1201, 1147, 1062, 1033, 1000, 877, 825, $743 \mathrm{~cm}^{-1}$; HRMS (ESI) calcd for $\mathrm{C}_{11} \mathrm{H}_{15} \mathrm{NO}_{3}+\mathrm{Na} 232.0944$, found 232.0942.

Methyl (S)-2-(2-formyl-1H-pyrrol-1-yl)-4-methylpentanoate (5d). The mixture of L-leucine methyl ester, ammonium chloride salt ( $2.00 \mathrm{~g}, 11.0 \mathrm{mmol}), \mathrm{Et}_{3} \mathrm{~N}(1.6 \mathrm{~mL}, 11.0 \mathrm{mmol})$, D-ribose $(3.32 \mathrm{~g}, 22.0 \mathrm{mmol})$, and oxalic acid $(0.99 \mathrm{~g}, 11.0 \mathrm{mmol})$ in dry DMSO $(10 \mathrm{~mL})$ was pressurized to 2.5 bar by argon and reacted at $80{ }^{\circ} \mathrm{C}$ for $30 \mathrm{~min}$ to give $5 \mathrm{~d}(1.55 \mathrm{~g}, 6.93 \mathrm{mmol})$ in $63 \%$ yield as light-brown liquid after purification by $\mathrm{SiO}_{2}$ column chromatography.

Data for $5 \boldsymbol{d}$. $R_{\mathrm{f}}=0.76$ (4: 6 EtOAc/hexane); ${ }^{1} \mathrm{H}$ NMR $\delta=0.90$ $(\mathrm{d}, J=6.8 \mathrm{~Hz}, 3 \mathrm{H}), 0.93(\mathrm{~d}, J=6.8 \mathrm{~Hz}, 3 \mathrm{H}), 1.40(\mathrm{~m}, 1 \mathrm{H}), 1.99$ $(\mathrm{dd}, J=8.0,6.8 \mathrm{~Hz}, 2 \mathrm{H}), 3.72(\mathrm{~s}, 3 \mathrm{H}), 6.10(\mathrm{t}, J=8.0 \mathrm{~Hz}, 1 \mathrm{H}), 6.32$ (dd, $J=4.0,2.8 \mathrm{~Hz}, 1 \mathrm{H}), 6.96(\mathrm{dd}, J=4.0,1.6 \mathrm{~Hz}, 1 \mathrm{H}), 7.21$ (ddd, $J=2.8,1.6,1.2 \mathrm{~Hz}, 1 \mathrm{H}), 9.52(\mathrm{~d}, J=1.2 \mathrm{~Hz}, 1 \mathrm{H}) \mathrm{ppm} ;{ }^{13} \mathrm{C} \mathrm{NMR}$ $\delta=21.3,22.8,24.6,41.3,52.4,57.4,110.4,125.5,129.5,131.6$, 171.5, 179.6 ppm; IR $\nu=3119,2963,2873,2810,2773,2729$, $1750,1657,1534,1473,1411,1373,1348,1273,1203,1164$, 1132, 1080, 1029, 1001, 911, 878, 832, 778, $753 \mathrm{~cm}^{-1}$; HRMS (EI) calcd for $\mathrm{C}_{12} \mathrm{H}_{17} \mathrm{NO}_{3} 223.1208$, found 223.1207.

Methyl (2S,3S)-2-(2-formyl-1H-pyrrol-1-yl)-3-methylpentanoate (5e). The mixture of L-isoleucine methyl ester, ammonium chloride salt (2.00 g, $11.0 \mathrm{mmol}), \mathrm{Et}_{3} \mathrm{~N}(1.5 \mathrm{~mL}, 11.0 \mathrm{mmol})$, D-ribose $(3.31 \mathrm{~g}, 22.0 \mathrm{mmol})$, and oxalic acid $(0.88 \mathrm{~g}, 11.0 \mathrm{mmol})$ in dry DMSO $(10 \mathrm{~mL})$ was pressurized to 2.5 bar by argon and reacted at $80{ }^{\circ} \mathrm{C}$ for $30 \mathrm{~min}$ to give $5 \mathrm{e}$ (982 $\mathrm{mg}, 4.4 \mathrm{mmol}$ ) in $40 \%$ yield as light-brown liquid after purification by $\mathrm{SiO}_{2}$ column chromatography.

Data for 5e. $R_{\mathrm{f}}=0.80$ (4:6 EtOAc/hexane); ${ }^{1} \mathrm{H}$ NMR $\delta=0.83$ $(\mathrm{t}, J=7.2 \mathrm{~Hz}, 3 \mathrm{H}), 0.98(\mathrm{~d}, J=6.8 \mathrm{~Hz}, 3 \mathrm{H}), 1.00-1.24(\mathrm{~m}, 2 \mathrm{H})$, $2.18(\mathrm{~m}, 1 \mathrm{H}), 3.74(\mathrm{~s}, 3 \mathrm{H}), 6.06(\mathrm{~d}, J=9.6 \mathrm{~Hz}, 1 \mathrm{H}), 6.31$ (dd, $J=$ 
3.2, $2.4 \mathrm{~Hz}, 1 \mathrm{H}), 6.93(\mathrm{dd}, J=3.2,1.6 \mathrm{~Hz}, 1 \mathrm{H}), 7.41$ (ddd, $J=2.4$, 1.6, $1.2 \mathrm{~Hz}, 1 \mathrm{H}), 9.53$ (s, 1H) ppm; ${ }^{13} \mathrm{C} \mathrm{NMR} \delta=10.5,15.3,24.7$, 38.8, 52.0, 62.6, 110.5, 125.2, 129.7, 131.8, 171.0, 179.6 ppm; IR $\nu$ $=3116,2961,2862$, 2703, 1735, 1655, 1530, 1468, 1410, 1375, 1343, 1250, 1202, 1151, 1070, 1026, 991, $750 \mathrm{~cm}^{-1}$; HRMS (EI) calcd for $\mathrm{C}_{12} \mathrm{H}_{17} \mathrm{NO}_{3}$ 223.1208, found 223.1207; HRMS (ESI) calcd for $\mathrm{C}_{12} \mathrm{H}_{17} \mathrm{NO}_{3}+\mathrm{Na} 246.1101$, found 246.1105.

Methyl (S)-2-(2-formyl-1H-pyrrol-1-yl)-3-phenylpropanoate (5f). The mixture of L-phenylalanine methyl ester, ammonium chloride salt $(2.00 \mathrm{~g}, 9.3 \mathrm{mmol}), \mathrm{Et}_{3} \mathrm{~N}(1.3 \mathrm{~mL}, 9.3 \mathrm{mmol}), \mathrm{D}^{-}$ ribose $(2.80 \mathrm{~g}, 18.6 \mathrm{mmol})$, and oxalic acid ( $0.84 \mathrm{~g}, 9.3 \mathrm{mmol})$ in dry DMSO $(10 \mathrm{~mL})$ was pressurized to 2.5 bar by argon and reacted at $80{ }^{\circ} \mathrm{C}$ for $30 \mathrm{~min}$ to give $5 \mathbf{f}(1.29 \mathrm{~g}, 5.02 \mathrm{mmol})$ in $54 \%$ yield as light-brown liquid after purification by $\mathrm{SiO}_{2}$ column chromatography.

Data for $5 \boldsymbol{f}$. $R_{\mathrm{f}}=0.88$ (4: 6 EtOAc/hexane); ${ }^{1} \mathrm{H}$ NMR $\delta=3.27$ (dd, $J=14.0,10.0 \mathrm{~Hz}, 1 \mathrm{H}), 3.54(\mathrm{dd}, J=14.0,5.6 \mathrm{~Hz}, 1 \mathrm{H}), 3.74(\mathrm{~s}$, $3 \mathrm{H}$ ), 6.06 (br s or dd, $J=10.0,5.6 \mathrm{~Hz}$, calcd. $1 \mathrm{H}), 6.21$ (dd, $J=$ $4.0,2.8 \mathrm{~Hz}, 1 \mathrm{H}), 6.91(\mathrm{dd}, J=4.0,1.6 \mathrm{~Hz}, 1 \mathrm{H}), 6.98-7.03(\mathrm{~m}, 3 \mathrm{H})$, $7.15-7.23(\mathrm{~m}, 3 \mathrm{H}), 9.43(\mathrm{~d}, J=0.8 \mathrm{~Hz}, 1 \mathrm{H}) \mathrm{ppm} ;{ }^{13} \mathrm{C} \mathrm{NMR} \delta=$ 39.0, 52.6, 61.1, 110.2, 125.6, 126.9, 128.4, 128.9, 130.6, 131.2, 136.0, 170.3, $179.5 \mathrm{ppm}$; IR $\nu=3114,3067,3029,2955,2845$, 2812, 1740, 1654, 1530, 1500, 1472, 1409, 1373, 1343, 1277, 1215, 1079, 1032, 1002, 744, $698 \mathrm{~cm}^{-1}$; HRMS (EI) calcd for $\mathrm{C}_{15} \mathrm{H}_{15} \mathrm{NO}_{3}+\mathrm{Na} 280.0944$, found 280.0948.

Methyl (S)-2-(2-formyl-1H-pyrrol-1-yl)-4-phenylbutanoate (5g). The mixture of L-homophenylalanine methyl ester, ammonium chloride salt $(2.00 \mathrm{~g}, 8.7 \mathrm{mmol}), \mathrm{Et}_{3} \mathrm{~N}(1.2 \mathrm{~mL}, 8.7$ $\mathrm{mmol})$, D-ribose $(2.62 \mathrm{~g}, 17.4 \mathrm{mmol})$, and oxalic acid $(0.79 \mathrm{~g}, 8.7$ $\mathrm{mmol})$ in dry DMSO $(10 \mathrm{~mL})$ was pressurized to 2.5 bar by argon and reacted at $80{ }^{\circ} \mathrm{C}$ for $30 \mathrm{~min}$ to give $5 \mathrm{~g}(1.25 \mathrm{~g}, 4.6 \mathrm{mmol})$ in $53 \%$ yield as light-yellow liquid after purification by $\mathrm{SiO}_{2}$ column chromatography.

Data for $5 g$. $R_{\mathrm{f}}=0.71$ (4: 6 EtOAc/hexane); ${ }^{1} \mathrm{H}$ NMR $\delta=2.26-$ $2.36(\mathrm{~m}, 1 \mathrm{H}), 2.45-2.60(\mathrm{~m}, 3 \mathrm{H}), 3.70(\mathrm{~s}, 3 \mathrm{H}), 5.89(\mathrm{br} \mathrm{d}, J=$ $8.0 \mathrm{~Hz}, 1 \mathrm{H}), 6.34(\mathrm{dd}, J=4.0,2.8 \mathrm{~Hz}, 1 \mathrm{H}), 6.98(\mathrm{dd}, J=4.0$, $1.6 \mathrm{~Hz}, 1 \mathrm{H}), 7.07-7.12(\mathrm{~m}, 2 \mathrm{H}), 7.15-7.20(\mathrm{~m}, 2 \mathrm{H}), 7.22-7.28(\mathrm{~m}$, $2 \mathrm{H}), 9.51(\mathrm{~d}, J=1,2 \mathrm{~Hz}, 1 \mathrm{H}) \mathrm{ppm} ;{ }^{13} \mathrm{C}$ NMR $\delta=31.8,34.0,52.5$, 58.9, 110.5, 125.5, 126.2, 128.2 , 128.4, 129.7, 131.6, 140.0, 170.8, 179.6 ppm; IR $\nu=3114,3067,3027,2955,2847,2810,1735$, $1644,1532,1502,1472,1413,1375,1340,1254,1209,1179$, 1087, 1031, 1008, 734, $686 \mathrm{~cm}^{-1}$; HRMS (FAB) calcd for $\mathrm{C}_{16} \mathrm{H}_{18} \mathrm{NO}_{3}$ 272.1287, found 272.1284.

Dimethyl (S)-2-(2-formyl-1H-pyrrol-1-yl)succinate (5h). The mixture of $\mathrm{L}$-aspartic acid dimethyl ester, ammonium chloride salt (2.00 g, $10.1 \mathrm{mmol}), \mathrm{Et}_{3} \mathrm{~N}(1.4 \mathrm{~mL}, 10.1 \mathrm{mmol})$, D-ribose (3.04 g, $20.2 \mathrm{mmol})$, and oxalic acid $(0.92 \mathrm{~g}, 10.1 \mathrm{mmol})$ in dry DMSO $(10 \mathrm{~mL})$ was pressurized to 2.5 bar by argon and reacted at $80{ }^{\circ} \mathrm{C}$ for $30 \mathrm{~min}$ to give $5 \mathrm{~h}(1.14 \mathrm{~g}, 4.76 \mathrm{mmol})$ in $47 \%$ yield as light-brown liquid after purification by $\mathrm{SiO}_{2}$ column chromatography.

Data for 5 h. $R_{\mathrm{f}}=0.45$ (4: 6 EtOAc/hexane); ${ }^{1} \mathrm{H}$ NMR $\delta=3.06$ (dd, $J=17.2,8.4 \mathrm{~Hz}, 1 \mathrm{H}), 3.39$ (dd, $J=17.2,4.8 \mathrm{~Hz}, 1 \mathrm{H}), 3.66$ (s, $3 \mathrm{H}), 3.74(\mathrm{~s}, 3 \mathrm{H}), 5.42$ (d, $J=14.8 \mathrm{~Hz}, 1 \mathrm{H}), 5.87$ (br s, 1H), 6.29 (dd, $J=4.0,2.8 \mathrm{~Hz}, 1 \mathrm{H}), 7.01$ (dd, $J=4.0,1.6 \mathrm{~Hz}, 1 \mathrm{H}$ ), 7.13 (ddd, $J=2.8,1.6,1.2 \mathrm{~Hz}, 1 \mathrm{H}), 9.48(\mathrm{~d}, J=1.2 \mathrm{~Hz}, 1 \mathrm{H}) \mathrm{ppm} ;{ }^{13} \mathrm{C} \mathrm{NMR}$ $\delta=37.1,52.1,52.9,57.5,110.2,125.9,131.0,131.9,169.2,170.7$,
$179.3 \mathrm{ppm}$; IR $\nu=3116,3002,2952,2848,2817,1737,1652$, 1533, 1474, 1433, 1413, 1370, 1339, 1276, 1221, 1166, 1084, 1039, 1008, $755 \mathrm{~cm}^{-1}$; HRMS (EI) calcd for $\mathrm{C}_{11} \mathrm{H}_{13} \mathrm{NO}_{5} 239.0794$, found 239.0797 .

Dimethyl $(S)$-2-(2-formyl-1H-pyrrol-1-yl)pentanedioate (5i). The mixture of L-glutamic acid dimethyl ester, ammonium chloride salt (2.00 g, $9.45 \mathrm{mmol}), \mathrm{Et}_{3} \mathrm{~N}(1.3 \mathrm{~mL}, 9.45 \mathrm{mmol}), \mathrm{D}^{-}$ ribose $(2.84 \mathrm{~g}, 18.9 \mathrm{mmol})$, and oxalic acid $(0.86 \mathrm{~g}, 9.45 \mathrm{mmol})$ in dry DMSO $(10 \mathrm{~mL})$ was pressurized to 2.5 bar by argon and reacted at $80{ }^{\circ} \mathrm{C}$ for $30 \mathrm{~min}$ to give $5 \mathbf{i}(885 \mathrm{mg}, 3.50 \mathrm{mmol})$ in $37 \%$ yield as light-brown liquid after purification by $\mathrm{SiO}_{2}$ column chromatography.

Data for $5 i$. $R_{\mathrm{f}}=0.46$ (4: 6 EtOAc/hexane); ${ }^{1} \mathrm{H}$ NMR $\delta=2.19-$ $2.37(\mathrm{~m}, 3 \mathrm{H}), 2.55-2.65(\mathrm{~m}, 1 \mathrm{H}), 3.65(\mathrm{~s}, 3 \mathrm{H}), 3.74(\mathrm{~s}, 3 \mathrm{H}), 5.95$ (br s, $1 \mathrm{H}), 6.33$ (dd, $J=4.0,2.8 \mathrm{~Hz}, 1 \mathrm{H}), 6.99(\mathrm{dd}, J=4.0,1.6 \mathrm{~Hz}, 1 \mathrm{H})$, 7.15 (ddd, $J=2.8,1.6,1.2 \mathrm{~Hz}, 1 \mathrm{H}), 9.51(\mathrm{~d}, J=1.2 \mathrm{~Hz}, 1 \mathrm{H}) \mathrm{ppm} ;{ }^{13} \mathrm{C}$ NMR $\delta=27.8,30.0,51.8,52.7,58.6,110.7,125.6,130.1,131.6$, 170.4, 172.6, 179.7 ppm; IR $\nu=3120,2996,2960,2927,2857,2811$, 2727, 1744, 1664, 1535, 1478, 1443, 1417, 1368, 1337, 1268, 1211, 1181, 1097, 1036, 1017, 887, 849, 834, $765 \mathrm{~cm}^{-1}$; HRMS (EI) calcd for $\mathrm{C}_{12} \mathrm{H}_{15} \mathrm{NO}_{5}$ 253.0950, found 253.0948.

Methyl

(S)-2-(2-formyl-1H-pyrrol-1-yl)-4-(methylthio) butanoate $(5 \mathbf{j})$. The mixture of L-methionine methyl ester, ammonium chloride salt ( $2.00 \mathrm{~g}, 10.0 \mathrm{mmol}), \mathrm{Et}_{3} \mathrm{~N}$ (1.4 mL, 10.1 $\mathrm{mmol})$, D-ribose $(3.01 \mathrm{~g}, 20.0 \mathrm{mmol})$, and oxalic acid $(0.90 \mathrm{~g}, 10.0$ $\mathrm{mmol})$ in dry DMSO $(10 \mathrm{~mL})$ was pressurized to 2.5 bar by argon and reacted at $80{ }^{\circ} \mathrm{C}$ for $30 \mathrm{~min}$ to give $5 \mathrm{j}(1.11 \mathrm{~g}, 4.60 \mathrm{mmol})$ in $46 \%$ yield as light-yellow liquid after purification by $\mathrm{SiO}_{2}$ column chromatography.

Data for $5 j . R_{\mathrm{f}}=0.59$ (4:6 EtOAc/hexane); ${ }^{1} \mathrm{H}$ NMR $\delta=2.07$ (s, 3H), 2.21-2.36 (m, 2H), 2.36-2.44 (m, 1H), 2.48-2.58 (m, 1H), 3.74 (s, 3H), 5.91 (br s, 1H), 6.33 (dd, $J=4.0,2.8 \mathrm{~Hz}, 1 \mathrm{H}), 7.00$ $(\mathrm{dd}, J=4.0,1.6 \mathrm{~Hz}, 1 \mathrm{H}), 7.16(\mathrm{dd}, J=2.8,1.6 \mathrm{~Hz}, 1 \mathrm{H}) \mathrm{ppm} ;{ }^{13} \mathrm{C}$ NMR $\delta=16.2,30.1,31.4,52.7,58.7,110.5,110.0,125.7,130.5$, 131.5, 170.5, 179.5 ppm; IR $\nu=3112,2946,2918,2843,2817$, 1741, 1650, 1532, 1472, 1407, 1373, 1342, 1272, 1226, 1208, 1085, 1031, 1003, $750 \mathrm{~cm}^{-1}$; HRMS (EI) calcd for $\mathrm{C}_{11} \mathrm{H}_{15} \mathrm{NO}_{3} \mathrm{~S}$ 241.0773, found 241.0771.

Methyl (S)-2-(2-formyl-1H-pyrrol-1-yl)-3-(1H-indol-3-yl) propanoate $(5 \mathbf{k})$. The mixture of $\mathrm{L}$-tryptophan methyl ester, ammonium chloride salt ( $2.00 \mathrm{~g}, 7.85 \mathrm{mmol}), \mathrm{Et}_{3} \mathrm{~N}$ (1.1 mL, 7.85 $\mathrm{mmol})$, D-ribose $(2.36 \mathrm{~g}, 15.7 \mathrm{mmol})$, and oxalic acid $(0.71 \mathrm{~g}, 7.85$ $\mathrm{mmol})$ in dry DMSO $(10 \mathrm{~mL})$ was pressurized to 2.5 bar by argon and reacted at $80{ }^{\circ} \mathrm{C}$ for $30 \mathrm{~min}$ to give $5 \mathbf{k}(1.28 \mathrm{~g}, 4.32 \mathrm{mmol})$ in $55 \%$ yield as light-yellow liquid after purification by $\mathrm{SiO}_{2}$ column chromatography.

Data for $5 \boldsymbol{k} . R_{\mathrm{f}}=0.40$ (4: 6 EtOAc/hexane); ${ }^{1} \mathrm{H}$ NMR $\delta=3.47$ (dd, $J=14.4,9.2 \mathrm{~Hz}, 1 \mathrm{H}), 3.71(\mathrm{dd}, J=14.4,5.6 \mathrm{~Hz}, 1 \mathrm{H}), 3.73$ (s, $3 \mathrm{H}), 6.09$ (br s, 1H), 6.17 (dd, $J=3.6,2.4 \mathrm{~Hz}, 1 \mathrm{H}), 6.71$ (d, $J=$ $2.4 \mathrm{~Hz}, 1 \mathrm{H}$ ), 6.93 (dd, $J=3.6,1.6 \mathrm{~Hz}, 1 \mathrm{H}$ ), 7.01 (br s, 1H), 7.11 (ddd, $J=8.4,6.8,0.8 \mathrm{~Hz}, 1 \mathrm{H}), 7.18$ (ddd, $J=8.4,6.8,1.2 \mathrm{~Hz}, 1 \mathrm{H}$ ), 7.31 (d, $J=8.4 \mathrm{~Hz}, 1 \mathrm{H}), 7.54$ (d, $J=8.4 \mathrm{~Hz}, 1 \mathrm{H}), 7.99$ (br s, 1H), $9.48(\mathrm{~d}, J=1,2 \mathrm{~Hz}, 1 \mathrm{H}) \mathrm{ppm} ;{ }^{13} \mathrm{C}$ NMR $\delta=28.6,52.6,60.5$, $110.0,110.3,111.1,118.3,119.6,122.1,122.7,125.7,127.0$, 130.8, 131.2, 135.9, 170.6, 179.5 ppm; IR $\nu=3017,2872,1743$, 1658, 1457, 1402, 1372, 1345, 1223, 1151, 1092, 1079, 1034, 997, 
977, 912, 758, 733 703, 666, $651 \mathrm{~cm}^{-1}$; HRMS (FAB) calcd for $\mathrm{C}_{17} \mathrm{H}_{17} \mathrm{~N}_{2} \mathrm{O}_{3}$ 297.1239, found 297.1237.

\section{General procedure for reductive amination of pyrralines 5 with benzylamine}

2-Benzyl-1,2-dihydropyrrolo[1,2-a]pyrazin-3(4H)-one (6a). The mixture of methyl 2-(2-formyl- $1 H$-pyrrol-1-yl)acetate (5a) $(120 \mathrm{mg}, 0.72 \mathrm{mmol}$ ) and benzylamine (116 $\mathrm{mg}, 1.08 \mathrm{mmol}$ ) in $\mathrm{MeOH}(5 \mathrm{~mL})$ was stirred at room temperature for $12 \mathrm{~h}$, and then $\mathrm{NaBH}_{4}(20 \mathrm{mg}, 0.53 \mathrm{mmol})$ was added at $0{ }^{\circ} \mathrm{C}$. The mixture was stirred at $0{ }^{\circ} \mathrm{C}$ for $9 \mathrm{~h}$, quenched with $10 \% \mathrm{NaHCO}_{3}$ solution, and extracted with EtOAc. The organic layer was washed with brine and $\mathrm{H}_{2} \mathrm{O}$, dried over anhydrous $\mathrm{Na}_{2} \mathrm{SO}_{4}$, filtered, and concentrated under reduced pressure to give the crude product, which was treated with DBU $(0.53 \mathrm{~g}, 3.48 \mathrm{mmol})$ in toluene (10 $\mathrm{mL})$. The mixture was heated at $120^{\circ} \mathrm{C}$ for $12 \mathrm{~h}$ and cooled to room temperature. The reaction mixture was concentrated under reduced pressure and purified by $\mathrm{SiO}_{2}$ flash column chromatography to give $\mathbf{6 a}(59 \mathrm{mg}, 0.26 \mathrm{mmol})$ in $36 \%$ yield as light-yellow liquid.

Data for $6 a$. ${ }^{1} \mathrm{H}-\mathrm{NMR} \delta=4.43(\mathrm{~s}, 2 \mathrm{H}), 4.70(\mathrm{~s}, 2 \mathrm{H}), 4.75(\mathrm{~s}, 2 \mathrm{H})$, $5.91(\mathrm{dd}, J=2.4,1.6 \mathrm{~Hz}, 1 \mathrm{H}), 6.21(\mathrm{dd}, J=3.6,2.4 \mathrm{~Hz}, 1 \mathrm{H}), 6.61$ (dd, $J=2.4,1.6 \mathrm{~Hz}, 1 \mathrm{H}), 7.26-7.37$ (m, 5H) ppm; ${ }^{13} \mathrm{C}-\mathrm{NMR} \delta=$ 44.2, 48.4, 50.0, 103.2, 109.6, 118.0, 121.9, 127.9, 128.2, 128.8, 135.8, 164.6 ppm; IR (neat) $\nu=3034,2926,2848,1715,1651$, 1543, 1491, 1450, 1424, 1323, 1256, 1204, 1182, 1073, 1025, 950, 902, 816, 742, 697, $608 \mathrm{~cm}^{-1}$; HRMS (ESI) calcd for $\mathrm{C}_{14} \mathrm{H}_{14} \mathrm{~N}_{2} \mathrm{O}+$ Na 249.0998, found 249.1001.

(S)-2-Benzyl-4-methyl-1,2-dihydropyrrolo[1,2-a]pyrazin$3(4 H)$-one (6b). The reaction of methyl $(S)$-2-(2-formyl-1H-pyrrol1-yl)propanoate (5b) (120 mg, $0.66 \mathrm{mmol})$ and benzylamine $(106 \mathrm{mg}, 0.99 \mathrm{mmol})$ in $\mathrm{MeOH}(5 \mathrm{~mL})$ at room temperature for $12 \mathrm{~h}$, followed by $\mathrm{NaBH}_{4}(20 \mathrm{mg}, 0.53 \mathrm{mmol})$ reduction at $0{ }^{\circ} \mathrm{C}$ for $9 \mathrm{~h}$, and then cyclization by DBU $(0.50 \mathrm{~g}, 3.28 \mathrm{mmol})$ in toluene $(10 \mathrm{~mL})$ at $120{ }^{\circ} \mathrm{C}$ for $12 \mathrm{~h}$ produced $6 \mathrm{~b}(105 \mathrm{mg}, 0.44$ $\mathrm{mmol}$ ) in $66 \%$ yield as light-yellow liquid after purification by $\mathrm{SiO}_{2}$ column chromatography.

Data for $6 \boldsymbol{b} .{ }^{1} \mathrm{H}-\mathrm{NMR} \delta=1.68(\mathrm{~d}, J=7.2 \mathrm{~Hz}, 3 \mathrm{H}), 4.36$ (A of $\mathrm{ABq}, J=15.2 \mathrm{~Hz}, 1 \mathrm{H}), 4.42(\mathrm{~B}$ of ABq, $J=15.2 \mathrm{~Hz}, 1 \mathrm{H}), 4.72(\mathrm{~s}$, $2 \mathrm{H}), 4.74(\mathrm{q}, J=7.2 \mathrm{~Hz}, 1 \mathrm{H}), 5.89(\mathrm{~m}, 1 \mathrm{H}), 6.20(\mathrm{dd}, J=3.6$, $2.8 \mathrm{~Hz}, 1 \mathrm{H}), 6.64(\mathrm{dd}, J=2.8,2.0 \mathrm{~Hz}, 1 \mathrm{H}), 7.24-7.36(\mathrm{~m}$, $5 \mathrm{H}) \mathrm{ppm} ;{ }^{13} \mathrm{C}-\mathrm{NMR} \delta=20.2,43.8,50.2,54.7,103.1,109.4,117.0$, 121.6, 127.7, 128.0, 128.7, 135.9, $168.1 \mathrm{ppm}$; IR (neat) $\nu=3068$, 3030, 2974, 2926, 2848, 1711, 1651, 1543, 1483, 1450, 1319, 1256, 1204, 1144, 1073, 1029, 965, 932, 896, 738, 697, $611 \mathrm{~cm}^{-1}$; HRMS (ESI) calcd for $\mathrm{C}_{15} \mathrm{H}_{16} \mathrm{~N}_{2} \mathrm{O}+\mathrm{Na} 263.1155$, found 263.1158 .

(S)-2-Benzyl-4-isopropyl-1,2-dihydropyrrolo[1,2-a]pyrazin$3(4 H)$-one (6c). The reaction of methyl $(S)$-2-(2-formyl-1H-pyrrol1-yl)-3-methylbutanoate (5c) (120 mg, $0.57 \mathrm{mmol})$ and benzylamine ( $87 \mathrm{mg}, 0.81 \mathrm{mmol})$ in $\mathrm{MeOH}(5 \mathrm{~mL})$ at room temperature for $12 \mathrm{~h}$, followed by $\mathrm{NaBH}_{4}(16 \mathrm{mg}, 0.43 \mathrm{mmol})$ reduction at $0{ }^{\circ} \mathrm{C}$ for $9 \mathrm{~h}$, and then cyclization by DBU $(0.41 \mathrm{~g}, 2.69 \mathrm{mmol})$ in toluene $(10 \mathrm{~mL})$ at $120{ }^{\circ} \mathrm{C}$ for $12 \mathrm{~h}$ produced $6 \mathrm{c}(112 \mathrm{mg}, 0.42$ $\mathrm{mmol}$ ) in $73 \%$ yield as light-yellow liquid after purification by $\mathrm{SiO}_{2}$ column chromatography.
Data for $6 c .{ }^{1} \mathrm{H}-\mathrm{NMR} \delta=0.84(\mathrm{~d}, J=7.2 \mathrm{~Hz}, 3 \mathrm{H}), 1.06(\mathrm{~d}, J=$ $7.2 \mathrm{~Hz}, 3 \mathrm{H}$ ), 2.39 (m, 1H), 4.27 (A of ABq, $J=15.6 \mathrm{~Hz}, 1 \mathrm{H}$ ), 4.39 (B of ABq, $J=15.6 \mathrm{~Hz}, 1 \mathrm{H}$ ), 4.52 (d, $J=4.4 \mathrm{~Hz}, 1 \mathrm{H}$ ), 4.59 (A of $\mathrm{ABq}, J=14.8 \mathrm{~Hz}, 1 \mathrm{H}), 4.82$ (B of ABq, $J=14.8 \mathrm{~Hz}, 1 \mathrm{H}$ ), 5.89 (dd, $J$ $=3.6,1.6 \mathrm{~Hz}, 1 \mathrm{H}), 6.16(\mathrm{dd}, J=3.6,2.8 \mathrm{~Hz}, 1 \mathrm{H}), 6.57(\mathrm{dd}, J=2.8$, $1.6 \mathrm{~Hz}, 1 \mathrm{H}), 7.22-7.34$ (m, 5H) ppm; ${ }^{13} \mathrm{C}-\mathrm{NMR} \delta=17.6,19.9$, 34.7, 44.2, 50.2, 65.2, 103.0, 108.6, 119.1, 122.5, 127.7, 128.2, 128.7, 136.0, 167.4 ppm; IR (neat) $\nu=3094,3027,2967,2933$, 2870, 1655, 1543, 1495, 1469, 1454, 1387, 1353, 1290, 1275, 1216, 1152, 1070, 991, 957, 891, 861, 790, 749, 716, 696, 662, $615 \mathrm{~cm}^{-1}$; HRMS (ESI) calcd for $\mathrm{C}_{17} \mathrm{H}_{20} \mathrm{~N}_{2} \mathrm{O}+\mathrm{Na} 291.1468$, found 291.1470.

(S)-2-Benzyl-4-((S)-sec-butyl)-1,2-dihydropyrrolo[1,2-a]pyrazin-3(4H)-one (6d). The reaction of methyl $(2 S, 3 S)$-2-(2-formyl$1 H$-pyrrol-1-yl)-3-methylpentanoate (5e) $(0.12 \mathrm{~g}, 0.54 \mathrm{mmol})$ and benzylamine (87 mg, $0.81 \mathrm{mmol})$ in $\mathrm{MeOH}(5 \mathrm{~mL})$ at room temperature for $12 \mathrm{~h}$, followed by $\mathrm{NaBH}_{4}(16 \mathrm{mg}, 0.43 \mathrm{mmol})$ reduction at $0{ }^{\circ} \mathrm{C}$ for $9 \mathrm{~h}$, and then cyclization by DBU $(0.41 \mathrm{~g}$, $2.69 \mathrm{mmol})$ in toluene $(10 \mathrm{~mL})$ at $120^{\circ} \mathrm{C}$ for $12 \mathrm{~h}$ produced $6 \mathrm{~d}$ (131 $\mathrm{mg}, 0.46 \mathrm{mmol}$ ) in 86\% yield as light-yellow liquid after purification by $\mathrm{SiO}_{2}$ column chromatography.

Data for $6 \boldsymbol{d} .{ }^{1} \mathrm{H}-\mathrm{NMR} \delta=0.90(\mathrm{t}, J=7.2 \mathrm{~Hz}, 3 \mathrm{H}), 1.00(\mathrm{~d}, J=$ $6.8 \mathrm{~Hz}, 3 \mathrm{H}), 1.05-1.17(\mathrm{~m}, 1 \mathrm{H}), 1.49-1.60$ (m, 1H), 2.05-2.16 (m, $1 \mathrm{H}$ ), 4.30 (A of ABq, $J=15.2 \mathrm{~Hz}, 1 \mathrm{H}$ ), 4.43 (B of ABq, $J=15.2 \mathrm{~Hz}$, $1 \mathrm{H}), 4.62$ (d, $J=4.4 \mathrm{~Hz}, 1 \mathrm{H}), 4.67$ (A of ABq, $J=14.8 \mathrm{~Hz}, 1 \mathrm{H}$ ), 4.78 (B of ABq, $J=14.8 \mathrm{~Hz}, 1 \mathrm{H}), 5.89(\mathrm{dd}, J=3.2,2.0 \mathrm{~Hz}, 1 \mathrm{H})$, $6.18(\mathrm{dd}, J=3.2,2.8 \mathrm{~Hz}, 1 \mathrm{H}), 6.59$ (dd, $J=2.8,2.0 \mathrm{~Hz}, 1 \mathrm{H}), 7.26-$ $7.36(\mathrm{~m}, 5 \mathrm{H}) \mathrm{ppm} ;{ }^{13} \mathrm{C}-\mathrm{NMR} \delta=11.5,15.9,24.9,41.7,44.3,50.3$, 64.3, 103.0, 108.9, 118.8, 122.6, 127.8, 128.3, 128.7, 136.1, $167.2 \mathrm{ppm}$; IR (neat) $\nu=3019,2963,2926,2874,1707,1651$, 1543, 1487, 1454, 1323, 1215, 1141, 1073, 1029, 950, 928, 898, $742,697,667,634,611 \mathrm{~cm}^{-1}$; HRMS (ESI) calcd for $\mathrm{C}_{18} \mathrm{H}_{22} \mathrm{~N}_{2} \mathrm{O}+$ Na 305.1624, found 305.1628.

$(S)$-2,4-Dibenzyl-1,2-dihydropyrrolo[1,2-a]pyrazin-3(4H)-one (6e). The reaction of methyl $(S)$-2-(2-formyl-1H-pyrrol-1-yl)-3phenylpropanoate $(\mathbf{5 f})(120 \mathrm{mg}, 0.47 \mathrm{mmol})$ and benzylamine (76 mg, $0.71 \mathrm{mmol}$ ) in $\mathrm{MeOH}(5 \mathrm{~mL})$ at room temperature for $12 \mathrm{~h}$, followed by $\mathrm{NaBH}_{4}(17 \mathrm{mg}, 0.45 \mathrm{mmol})$ reduction at $0{ }^{\circ} \mathrm{C}$ for $9 \mathrm{~h}$, and then cyclization by DBU $(0.43 \mathrm{~g}, 2.82 \mathrm{mmol})$ in toluene $(10 \mathrm{~mL})$ at $120{ }^{\circ} \mathrm{C}$ for $12 \mathrm{~h}$ produced $6 \mathrm{e}(61 \mathrm{mg}, 0.19$ $\mathrm{mmol}$ ) in $41 \%$ yield as light-yellow liquid after purification by $\mathrm{SiO}_{2}$ column chromatography.

Data for $6 \boldsymbol{e}$. ${ }^{1} \mathrm{H}-\mathrm{NMR} \delta=3.09(\mathrm{~d}, J=15.2 \mathrm{~Hz}, 3 \mathrm{H}), 3.26(\mathrm{~d}$ of A of $\left.\mathrm{ABq}, J_{\mathrm{AB}}=13.6, J_{\mathrm{d}}=4.4 \mathrm{~Hz}, 1 \mathrm{H}\right), 3.41\left(\mathrm{~d}\right.$ of $\mathrm{B}$ of $\mathrm{ABq}, J_{\mathrm{AB}}=$ $\left.13.6, J_{\mathrm{d}}=4.4 \mathrm{~Hz}, 1 \mathrm{H}\right), 3.93(\mathrm{~d}, J=15.2 \mathrm{~Hz}, 1 \mathrm{H}), 4.39(\mathrm{~A}$ of ABq, $\left.J_{\mathrm{AB}}=14.8 \mathrm{~Hz}, 1 \mathrm{H}\right), 4.65\left(\mathrm{~B}\right.$ of ABq, $\left.J_{\mathrm{AB}}=14.8 \mathrm{~Hz}, 1 \mathrm{H}\right), 5.03(\mathrm{t}, J=$ $4.4 \mathrm{~Hz}, 1 \mathrm{H}), 5.71$ (dd, $J=3.6,1.6 \mathrm{~Hz}, 1 \mathrm{H}), 6.22(\mathrm{dd}, J=3.6$, $2.8 \mathrm{~Hz}, 1 \mathrm{H}), 6.62(\mathrm{dd}, J=2.8,1.6 \mathrm{~Hz}, 1 \mathrm{H}), 6.66-6.70(\mathrm{~m}, 2 \mathrm{H})$, 7.00-7.06 (m, 2H), 7.13-7.17 (m, 3H), 7.24-7.32 (m, 3H) ppm; ${ }^{13} \mathrm{C}-\mathrm{NMR} \delta=41.5,43.6,50.1$, 60.0, 102.4, 109.8, 116.9, 122.8, 127.2, 127.7, 128.1, 128.5, 128.6, 129.6, 134.9, 135.6, 166.6 ppm; IR (neat) $\nu=3068,3027,2933,2844,1647,1483,1439,1394$, 1327, 1252, 1204, 1170, 1077, 1029, 965, 898, 861, 742, 693, 663, $630,611 \mathrm{~cm}^{-1}$; HRMS (ESI) calcd for $\mathrm{C}_{21} \mathrm{H}_{20} \mathrm{~N}_{2} \mathrm{O}+\mathrm{Na} 339.1468$, found 339.1470. 
(S)-2-Benzyl-4-phenethyl-1,2-dihydropyrrolo[1,2-a]pyrazin$3(4 \mathrm{H})$-one (6f). The reaction of methyl $(S)$-2-(2-formyl-1H-pyrrol1-yl)-4-phenylbutanoate (5g) (120 mg, $0.44 \mathrm{mmol})$ and benzylamine (71 $\mathrm{mg}, 0.66 \mathrm{mmol})$ in $\mathrm{MeOH}(5 \mathrm{~mL})$ at room temperature for $12 \mathrm{~h}$, followed by $\mathrm{NaBH}_{4}(13 \mathrm{mg}, 0.34 \mathrm{mmol})$ reduction at $0{ }^{\circ} \mathrm{C}$ for $9 \mathrm{~h}$, and then cyclization by DBU $(0.34 \mathrm{~g}, 2.23 \mathrm{mmol})$ in toluene $(10 \mathrm{~mL})$ at $120{ }^{\circ} \mathrm{C}$ for $12 \mathrm{~h}$ produced $6 \mathrm{f}$ in $64 \%$ yield as light-yellow liquid after purification by $\mathrm{SiO}_{2}$ column chromatography.

Data for $6 f .{ }^{1} \mathrm{H}-\mathrm{NMR} \delta=2.25-2.40(\mathrm{~m}, 2 \mathrm{H}), 2.44-2.53(\mathrm{~m}, 1 \mathrm{H})$, 2.56-2.65 (m, 1H), 4.31 (A of ABq, $\left.J_{\mathrm{AB}}=15.6 \mathrm{~Hz}, 1 \mathrm{H}\right), 4.39$ (B of $\left.\mathrm{ABq}, J_{\mathrm{AB}}=15.6 \mathrm{~Hz}, 1 \mathrm{H}\right), 4.61\left(\mathrm{~A}\right.$ of $\left.\mathrm{ABq}, J_{\mathrm{AB}}=14.4 \mathrm{~Hz}, 1 \mathrm{H}\right), 4.74$ (B of $\left.\mathrm{ABq}, J_{\mathrm{AB}}=14.4 \mathrm{~Hz}, 1 \mathrm{H}\right), 4.75(\mathrm{dd}, J=5.6,5.2 \mathrm{~Hz}, 1 \mathrm{H}), 5.89$ (dd, $J=3.6,1.6 \mathrm{~Hz}, 1 \mathrm{H}), 6.21(\mathrm{dd}, J=3.6,2.8 \mathrm{~Hz}, 1 \mathrm{H}), 6.60(\mathrm{dd}, J$ $=2.8,1.6 \mathrm{~Hz}, 1 \mathrm{H}), 7.09-7.18(\mathrm{~m}, 3 \mathrm{H}), 7.21-7.33(\mathrm{~m}, 7 \mathrm{H}) \mathrm{ppm}$; ${ }^{13} \mathrm{C}-\mathrm{NMR} \delta=30.6,36.2,43.9,50.1,58.7,103.1,109.4,117.6$, $121.9,126.0$, 127.7, 128.0, 128.2, 128.3, 128.6, 135.9, 140.2, $167.2 \mathrm{ppm}$; IR (neat) $\nu=3067,3027,2922,2856,1652,1485$, 1452, 1328, 1256, 1078, 1026, 746, $698 \mathrm{~cm}^{-1}$; HRMS (ESI) calcd for $\mathrm{C}_{22} \mathrm{H}_{22} \mathrm{~N}_{2} \mathrm{O}+\mathrm{Na} 353.1624$, found 353.1626.

Methyl (S)-2-(2-benzyl-3-oxo-1,2,3,4-tetrahydropyrrolo[1,2-a] pyrazin-4-yl)acetate (6g). The reaction of methyl $(S)-2-(2-$ formyl-1 $H$-pyrrol-1-yl)succinate $(5 \mathbf{h})(120 \mathrm{mg}, 0.50 \mathrm{mmol})$ and benzylamine $(80 \mathrm{mg}, 0.75 \mathrm{mmol})$ in $\mathrm{MeOH}(5 \mathrm{~mL})$ at room temperature for $12 \mathrm{~h}$, followed by $\mathrm{NaBH}_{4}(15 \mathrm{mg}, 0.40 \mathrm{mmol})$ reduction at $0{ }^{\circ} \mathrm{C}$ for $9 \mathrm{~h}$, and then cyclization by DBU $(0.38 \mathrm{~g}$, $2.50 \mathrm{mmol})$ in toluene $(10 \mathrm{~mL})$ at $120{ }^{\circ} \mathrm{C}$ for $12 \mathrm{~h}$ produced $6 \mathrm{~g}$ (125 mg, $0.42 \mathrm{mmol}$ ) in $84 \%$ yield as light-yellow liquid after purification by $\mathrm{SiO}_{2}$ column chromatography.

Data for $6 g$. ${ }^{1} \mathrm{H}-\mathrm{NMR} \delta=3.14$ (d of A of ABq, $J_{\mathrm{AB}}=16,8, J_{\mathrm{d}}=$ $4.8 \mathrm{~Hz}, 1 \mathrm{H}$ ), 3.18 (d of B of ABq, $J_{\mathrm{AB}}=16,8, J_{\mathrm{d}}=5.2 \mathrm{~Hz}, 1 \mathrm{H}$ ), 3,62 $(\mathrm{s}, 3 \mathrm{H}), 4.37\left(\mathrm{~d}\right.$ of $\mathrm{A}$ of $\left.\mathrm{ABq}, J_{\mathrm{AB}}=15.2, J_{\mathrm{d}}=0.8 \mathrm{~Hz}, 1 \mathrm{H}\right), 4.68(\mathrm{~B}$ of $\left.\mathrm{ABq}, J_{\mathrm{AB}}=15.2 \mathrm{~Hz}, 1 \mathrm{H}\right), 4.70\left(\mathrm{~A}\right.$ of $\left.\mathrm{ABq}, J_{\mathrm{AB}}=14.8 \mathrm{~Hz}, 1 \mathrm{H}\right), 4.79$ (B of $\left.\mathrm{ABq}, J_{\mathrm{AB}}=14.8 \mathrm{~Hz}, 1 \mathrm{H}\right), 5.05(\mathrm{dd}, J=5.2,4,8 \mathrm{~Hz}, 1 \mathrm{H}), 5.88$ $(\mathrm{dd}, J=3.6,1.6 \mathrm{~Hz}, 1 \mathrm{H}), 6.19(\mathrm{dd}, J=3.6,2.8 \mathrm{~Hz}, 1 \mathrm{H}), 6.63(\mathrm{dd}, J$ $=2.8,1.6 \mathrm{~Hz}, 1 \mathrm{H}), 7.26-7.37(\mathrm{~m}, 5 \mathrm{H}) \mathrm{ppm} ;{ }^{13} \mathrm{C}-\mathrm{NMR} \delta=38.3$, 44.0, 50.4, 52.0, 55.0, 103.3, 109.7, 117.3, 122.2, 127.7, 128.1, 128.7, 135.7, 166.4, $170.2 \mathrm{ppm}$; IR (neat) $\nu=3031,2923,2854$, 1735, 1654, 1487, 1437, 1370, 1330, 1249, 1201, 1168, 1077, $1018,987,896,744,699 \mathrm{~cm}^{-1}$; HRMS (ESI) calcd for $\mathrm{C}_{17} \mathrm{H}_{18} \mathrm{~N}_{2} \mathrm{O}_{3}$ $+\mathrm{Na} 321.1210$, found 321.1214.

(S)-2-Benzyl-4-(2-(methylthio)ethyl)-1,2-dihydropyrrolo[1,2a]pyrazin-3 $(4 H)$-one $(6 \mathbf{h})$. The reaction of methyl $(S)$-2-(2-formyl$1 H$-pyrrol-1-yl)-4-(methylthio)butanoate $\quad(5 \mathbf{j}) \quad(120 \mathrm{mg}, \quad 0.50$ $\mathrm{mmol})$ and benzylamine $(80 \mathrm{mg}, 0.75 \mathrm{mmol})$ in $\mathrm{MeOH}(5 \mathrm{~mL})$ at room temperature for $12 \mathrm{~h}$, followed by $\mathrm{NaBH}_{4}(15 \mathrm{mg}, 0.40$ mmol) reduction at $0{ }^{\circ} \mathrm{C}$ for $9 \mathrm{~h}$, and then cyclization by DBU $(0.38 \mathrm{~g}, 2.50 \mathrm{mmol})$ in toluene $(10 \mathrm{~mL})$ at $120{ }^{\circ} \mathrm{C}$ for $12 \mathrm{~h}$ produced $6 \mathrm{~h}$ (71 $\mathrm{mg}, 0.24 \mathrm{mmol}$ ) in $47 \%$ yield as light-yellow liquid after purification by $\mathrm{SiO}_{2}$ column chromatography.

Data for $6 \boldsymbol{h} .{ }^{1} \mathrm{H}-\mathrm{NMR} \delta=2.06(\mathrm{~s}, 3 \mathrm{H}), 2.23-2.33(\mathrm{~m}, 2 \mathrm{H}), 2.34-$ $2.49(\mathrm{~m}, 2 \mathrm{H}), 4.33$ (A of ABq, $J=15.6 \mathrm{~Hz}, 1 \mathrm{H}), 4.41(\mathrm{~B}$ of ABq, $J=$ $15.6 \mathrm{~Hz}, 1 \mathrm{H}), 4.67$ (A of ABq, $J=14.8 \mathrm{~Hz}, 1 \mathrm{H}), 4.73$ (B of ABq, $J=$ $14.8 \mathrm{~Hz}, 1 \mathrm{H}), 4.87(\mathrm{t}, J=5.6 \mathrm{~Hz}, 1 \mathrm{H}), 5.89(\mathrm{dd}, J=2.8,1.6 \mathrm{~Hz}$, $1 \mathrm{H}), 6.19(\mathrm{dd}, J=3.6,2.8 \mathrm{~Hz}, 1 \mathrm{H}), 6.63(\mathrm{dd}, J=2.8,1.6 \mathrm{~Hz}, 1 \mathrm{H})$, 7.24-7.36 (m, 5H) ppm; ${ }^{13} \mathrm{C}-\mathrm{NMR} \delta=15.2$, 29.2, 33.6, 44.0, 50.4,
58.0, 103.4, 109.6, 117.9, 122.1, 127.9, 128.2, 128.8, 136.0, 167.3 ppm; IR (neat) $\nu=3008,2915,2837,1647,1483,1431$, 1331, 1286, 1252, 1159, 1073, 1025, 950, 898, 820, 742, 697, 626, $611 \mathrm{~cm}^{-1}$; HRMS (ESI) calcd for $\mathrm{C}_{17} \mathrm{H}_{20} \mathrm{~N}_{2} \mathrm{OS}+\mathrm{Na} 323.1189$, found 323.1192.

\section{General procedure for cyclization of pyrralines 5 with ethane- 1,2-diamine}

1,2,3,10b-Tetrahydroimidazo[1,2-a]pyrrolo[2,1-c]pyrazin$\mathbf{5}(\mathbf{6 H})$-one (7a). The mixture of methyl 2-(2-formyl-1 $\mathrm{H}$-pyrrol-1yl)acetate (5a) $(1.00 \mathrm{~g}, 5.98 \mathrm{mmol})$ and ethane-1,2-diamine (360 mg, $5.99 \mathrm{mmol})$ in $\mathrm{MeOH}(10 \mathrm{~mL})$ was heated at $70{ }^{\circ} \mathrm{C}$ for $1 \mathrm{~h}$ and cooled to room temperature. The reaction mixture was concentrated under reduced pressure and purified by $\mathrm{SiO}_{2}$ flash column chromatography to give $7 \mathrm{a}(615 \mathrm{mg}, 3.47 \mathrm{mmol})$ in $58 \%$ yield as white solid.

Data for 7a. ${ }^{1} \mathrm{H}-\mathrm{NMR} \delta=2.14$ (br s, $\left.1 \mathrm{H}\right), 3.18-3.30(\mathrm{~m}, 1 \mathrm{H})$, 3.48-3.62 (m, 3H), 4.55 (A of ABq, $J=16.8 \mathrm{~Hz}, 1 \mathrm{H}$ ), 4.60 (B of $\mathrm{ABq}, J=16.8 \mathrm{~Hz}, 1 \mathrm{H}), 5.25$ (br s, $1 \mathrm{H}), 6.22-6.26(\mathrm{~m}, 2 \mathrm{H}), 6.66$ $(\mathrm{dd}, J=2.0,1.6 \mathrm{~Hz}, 1 \mathrm{H}) \mathrm{ppm} ;{ }^{13} \mathrm{C}-\mathrm{NMR} \delta=43.9,45.0,49.0,70.4$, 104.2, 109.5, 119.1, 124.8, 162.1 ppm; IR (KBr) $\nu=3226,3115$, 3098, 2976, 2960, 2885, 2857, 1636, 1470, 1441, 1305, 1216, 1173, 1159, 1126, 1070, 1004, 968, 951, 932, 906, 856, 770, 756, $729,681 \mathrm{~cm}^{-1}$; HRMS (ESI) calcd for $\mathrm{C}_{9} \mathrm{H}_{11} \mathrm{~N}_{3} \mathrm{O}+\mathrm{Na} 200.0794$, found 200.0797 .

(6S)-6-Methyl-1,2,3,10b-tetrahydroimidazo[1,2-a]pyrrolo[2,1c]pyrazin-5(6H)-one (7b). The reaction of methyl $(S)$-2-(2-formyl$1 H$-pyrrol-1-yl)propanoate (5b) $(1.00 \mathrm{~g}, 5.52 \mathrm{mmol})$ and ethane1,2-diamine (332 mg, $5.52 \mathrm{mmol})$ in $\mathrm{MeOH}(10 \mathrm{~mL})$ at $70{ }^{\circ} \mathrm{C}$ for $1 \mathrm{~h}$ produced $7 \mathbf{b}(918 \mathrm{mg}, 4.80 \mathrm{mmol})$ in $87 \%$ yield (a $3: 1$ mixture of stereoisomers) as white solid after purification by $\mathrm{SiO}_{2}$ column chromatography.

Data for $7 \boldsymbol{b} .{ }^{1} \mathrm{H}-\mathrm{NMR}$ (major) $\delta=1.61(\mathrm{~d}, J=7.2 \mathrm{~Hz}, 3 \mathrm{H}), 2.14$ (br s, $1 \mathrm{H}), 3.20-3.31(\mathrm{~m}, 1 \mathrm{H}), 3.47-3.61(\mathrm{~m}, 3 \mathrm{H}), 4.68(\mathrm{q}, J=$ $7.2 \mathrm{~Hz}, 1 \mathrm{H}), 5.26$ (br s, 1H), 6.22-6.28 (m, 2H), 6.68 (dd, $J=2.4$, $2.0 \mathrm{~Hz}, 1 \mathrm{H}$ ) ppm; ${ }^{13} \mathrm{C}-\mathrm{NMR}$ (major) $\delta=21.2,43.8,44.8,55.8$, 69.7, 103.8, 109.3, 117.9, 124.2, 165.7 ppm; (minor) $\delta=14.6$, 44.2, 44.8, 53.4, 69.7, 103.9, 108.7, 116.9, 125.9, 164.6 ppm; IR $(\mathrm{KBr}) \nu=3065,3030,2946,2920,2872,2844,1648,1543,1486$, 1460, 1431, 1357, 1329, 1252, 1221, 1140, 1073, 1025, 962, 766, $739,700 \mathrm{~cm}^{-1}$; HRMS (ESI) calcd for $\mathrm{C}_{10} \mathrm{H}_{13} \mathrm{~N}_{3} \mathrm{O}+\mathrm{Na} 214.0951$, found 214.0954 .

(6S)-6-Isopropyl-1,2,3,10b-tetrahydroimidazo[1,2-a]pyrrolo [2,1-c]pyrazin-5(6H)-one (7c). The reaction of methyl $(S)-2-(2-$ formyl-1 $H$-pyrrol-1-yl)-3-methylbutanoate $(5 \mathrm{c})(1.00 \mathrm{~g}, 4.78$ $\mathrm{mmol}$ ) and ethane-1,2-diamine (287 $\mathrm{mg}, 4.78 \mathrm{mmol}$ ) in $\mathrm{MeOH}$ $(10 \mathrm{~mL})$ at $70{ }^{\circ} \mathrm{C}$ for $1 \mathrm{~h}$ produced $7 \mathrm{c}(985 \mathrm{mg}, 4.49 \mathrm{mmol})$ in $94 \%$ yield as white solid after purification by $\mathrm{SiO}_{2}$ column chromatography.

Data for $7 c .{ }^{1} \mathrm{H}-\mathrm{NMR} \delta=0.93(\mathrm{~d}, J=6.4 \mathrm{~Hz}, 3 \mathrm{H}), 1.08(\mathrm{~d}, J=$ $6.8 \mathrm{~Hz}, 3 \mathrm{H}), 2.10$ (br s, $1 \mathrm{H}), 2.22-2.34(\mathrm{~m}, 1 \mathrm{H}), 3.17-3.28(\mathrm{~m}, 1 \mathrm{H})$, $3.47-3.60(\mathrm{~m}, 3 \mathrm{H}), 4.39$ (d, $J=5.2 \mathrm{~Hz}, 1 \mathrm{H}), 5.25$ (s, 1H), 6.22 (dd, $J=3.6,2.0 \mathrm{~Hz}, 1 \mathrm{H}), 6.24(\mathrm{dd}, J=3.6,1.2 \mathrm{~Hz}, 1 \mathrm{H}), 6.64(\mathrm{dd}, J=$ 2.0, $1.2 \mathrm{~Hz}, 1 \mathrm{H}) \mathrm{ppm} ;{ }^{13} \mathrm{C}-\mathrm{NMR} \delta=18.1,19.6,34.3,44.2,45.0$, $66.3,70.4,103.8,108.7,120.0,125.6,165.1 \mathrm{ppm}$; IR $(\mathrm{KBr}) \nu=$ 3278, 2971, 2891, 1654, 1567, 1463, 1430, 1395, 1372, 1325, 
1303, 1251, 1221, 1178, 1153, 1112, 1075, 950, 922, 903, 855, 750, 717, $667 \mathrm{~cm}^{-1}$; HRMS (ESI) calcd for $\mathrm{C}_{12} \mathrm{H}_{17} \mathrm{~N}_{3} \mathrm{O}+\mathrm{Na}$ 242.1264, found 242.1265.

(6S)-6-((S)-sec-Butyl)-1,2,3,10b-tetrahydroimidazo[1,2-a]pyrrolo[2,1-c]pyrazin-5(6H)-one (7d). The reaction of methyl $(2 S, 3 S)$-2-(2-formyl-1 $H$-pyrrol-1-yl)-3-methylpentanoate $(1.00 \mathrm{~g}, 4.48 \mathrm{mmol})$ and ethane-1,2-diamine $(270 \mathrm{mg}, 4.48$ $\mathrm{mmol})$ in $\mathrm{MeOH}(10 \mathrm{~mL})$ at $70{ }^{\circ} \mathrm{C}$ for $1 \mathrm{~h}$ produced $7 \mathrm{~d}(951 \mathrm{mg}$, $4.08 \mathrm{mmol}$ ) in $91 \%$ yield as white solid after purification by $\mathrm{SiO}_{2}$ column chromatography.

Data for $7 \boldsymbol{d} .{ }^{1} \mathrm{H}-\mathrm{NMR} \delta=0.90(\mathrm{t}, J=7.2 \mathrm{~Hz}, 3 \mathrm{H}), 0.98(\mathrm{~d}, J=$ $7.2 \mathrm{~Hz}, 3 \mathrm{H}), 1.05-1.17(\mathrm{~m}, 1 \mathrm{H}), 1.49-1.61(\mathrm{~m}, 1 \mathrm{H}), 1.92-2.04(\mathrm{~m}$, 1H), 2.25 (br s, 1H), 3.13-3.24 (m, 1H), 3.42-3.56 (m, 3H), 4.42 $(\mathrm{d}, J=5.6 \mathrm{~Hz}, 1 \mathrm{H}), 5.21$ (br s, 1H), 6.17-6.21 (m, 2H), 6.62 (dd, $J$ $=2.0,2.0 \mathrm{~Hz}, 1 \mathrm{H}) \mathrm{ppm} ;{ }^{13} \mathrm{C}-\mathrm{NMR} \delta=11.1,15.3,24.7,40.8,44.0$, $44.7,65.0,70.2,103.5,108.6,119.3,125.4,164.6$ ppm; IR (KBr) $\nu$ $=3292,3103$, 2962, 2931, 2880, 2860, 1638, 1464, 1430, 1349, 1323, 1277, 1247, 1221, 1189, 1108, 1078, 1025, 958, 902, 877, $772,710 \mathrm{~cm}^{-1}$; HRMS (ESI) calcd for $\mathrm{C}_{13} \mathrm{H}_{19} \mathrm{~N}_{3} \mathrm{O}+\mathrm{Na} 256.1420$, found 256.1421 .

(6S)-6-Benzyl-1,2,3,10b-tetrahydroimidazo[1,2-a]pyrrolo[2,1c]pyrazin-5(6H)-one (7e). The reaction of methyl (S)-2-(2-formyl$1 H$-pyrrol-1-yl)-3-phenylpropanoate (5f) $(1.00 \mathrm{~g}, 3.89 \mathrm{mmol})$ and ethane-1,2-diamine (234 mg, $3.89 \mathrm{mmol})$ in $\mathrm{MeOH}(10 \mathrm{~mL})$ at $70{ }^{\circ} \mathrm{C}$ for $1 \mathrm{~h}$ produced $7 \mathrm{e}(894 \mathrm{mg}, 3.34 \mathrm{mmol})$ in $86 \%$ yield as white solid after purification by $\mathrm{SiO}_{2}$ column chromatography.

Data for $7 e .{ }^{1} \mathrm{H}-\mathrm{NMR} \delta=1.94$ (br s, 1H), 2.90-2.99 (m, 1H), 3.24 (d of A of ABq, $\left.J_{\mathrm{AB}}=13.6, J_{\mathrm{d}}=4.4 \mathrm{~Hz}, 1 \mathrm{H}\right), 3.30$ (d of B of $\left.\mathrm{ABq}, J_{\mathrm{AB}}=13.6, J_{\mathrm{d}}=4.8 \mathrm{~Hz}, 1 \mathrm{H}\right), 3.25-3.39(\mathrm{~m}, 2 \mathrm{H}), 3.43-3.52$ (m, 1H), 3.79 (s, 1H), 4.90 (dd, $J=4.8,4.4 \mathrm{~Hz}, 1 \mathrm{H}), 6.07$ (dd, $J=$ 3.6, $1.2 \mathrm{~Hz}, 1 \mathrm{H}), 6.23$ (dd, $J=3.6,2.8 \mathrm{~Hz}, 1 \mathrm{H}), 6.59$ (dd, $J=2.8$, $1.2 \mathrm{~Hz}, 1 \mathrm{H}), 6.74-6.79(\mathrm{~m}, 2 \mathrm{H}), 7.12-7.18$ (m, 2H), 7.19-7.24 (m, 1H) ppm; ${ }^{13} \mathrm{C}-\mathrm{NMR} \delta=41.4,43.6,44.7,61.3,69.6,103.5,109.7$, 118.2 , 125.6, 127.5, 128.2, 129.5, 134.8, 164.0 ppm; IR (KBr) $\nu=$ 3276, 3064, 3031, 2951, 2885, 2857, 1644, 1469, 1459, 1436, 1328, 1306, 1217, 1173, 1119, 1076, 942, 914, 773, 728, $696 \mathrm{~cm}^{-1}$; HRMS (ESI) calcd for $\mathrm{C}_{16} \mathrm{H}_{18} \mathrm{~N}_{3} \mathrm{O}[\mathrm{M}+1]^{+} 268.1444$, found 268.1448.

(6S)-6-Phenethyl-1,2,3,10b-tetrahydroimidazo[1,2-a]pyrrolo [2,1-c]pyrazin-5(6H)-one (7f). The reaction of methyl $(S)-2-(2-$ formyl-1 $H$-pyrrol-1-yl)-4-phenylbutanoate $(5 \mathrm{~g}) \quad(1.00 \mathrm{~g}, \quad 3.69$ $\mathrm{mmol}$ ) and ethane-1,2-diamine (222 $\mathrm{mg}, 3.69 \mathrm{mmol})$ in $\mathrm{MeOH}$ $(10 \mathrm{~mL})$ at $70{ }^{\circ} \mathrm{C}$ for $1 \mathrm{~h}$ produced $7 \mathbf{f}(914 \mathrm{mg}, 3.25 \mathrm{mmol})$ in $88 \%$ yield as white solid after purification by $\mathrm{SiO}_{2}$ column chromatography.

Data for $7 f .{ }^{1} \mathrm{H}-\mathrm{NMR} \delta=2.08$ (br s, $\left.1 \mathrm{H}\right), 2.14-2.24(\mathrm{~m}, 1 \mathrm{H})$, 2.25-2.35 (m, 1H), 2.58-2.67 (m, 1H), 2.68-2.77 (m, 1H), 3.17$3.28(\mathrm{~m}, 1 \mathrm{H}), 3.47-3.60(\mathrm{~m}, 3 \mathrm{H}), 4.63(\mathrm{dd}, J=6.8,6.4 \mathrm{~Hz}, 1 \mathrm{H})$, $5.24(\mathrm{~s}, 1 \mathrm{H}), 6.23-6.27(\mathrm{~m}, 2 \mathrm{H}), 6.66(\mathrm{dd}, J=2.4,1.6 \mathrm{~Hz}, 1 \mathrm{H})$, 7.13-7.21 (m, 3H), 7.24-7.30 (m, 2H) ppm; ${ }^{13} \mathrm{C}-\mathrm{NMR} \delta=31.3$, 36.7, 44.2, 45.0, 60.1, 70.2, 104.2, 109.4, 119.1, 125.1, 126.2, 128.3, 128.5, 140.0, 165.3 ppm; IR (KBr) $\nu=3276,3028,2950$, 2885, 2859, 1652, 1458, 1429, 1334, 1305, 1221, 1158, 1118, 1073, 912, 771, 752, $698 \mathrm{~cm}^{-1}$; HRMS (ESI) calcd for $\mathrm{C}_{17} \mathrm{H}_{20} \mathrm{~N}_{3} \mathrm{O}$ $[\mathrm{M}+1]^{+} 282.1601$, found 282.1604.

Methyl 2-((6S)-5-oxo-1,2,3,5,6,10b-hexahydroimidazo[1,2-a] pyrrolo[2,1-c]pyrazin-6-yl)acetate (7g). The reaction of dimethyl
(S)-2-(2-formyl-1 $H$-pyrrol-1-yl)succinate $(5 \mathbf{h})(1.00 \mathrm{~g}, 4.18 \mathrm{mmol})$ and ethane-1,2-diamine (251 $\mathrm{mg}, 4.18 \mathrm{mmol})$ in $\mathrm{MeOH}(10 \mathrm{~mL})$ at $70{ }^{\circ} \mathrm{C}$ for $1 \mathrm{~h}$ produced $7 \mathrm{~g}(750 \mathrm{mg}, 3.01 \mathrm{mmol})$ in $72 \%$ yield (a $3: 1$ mixture of stereoisomers) as white solid after purification by $\mathrm{SiO}_{2}$ column chromatography.

Data for $7 \mathrm{~g} .{ }^{1} \mathrm{H}-\mathrm{NMR}$ (major) $\delta=2.31$ (br s, 1H), 2.91 (d of A of $\left.\mathrm{ABq}, J_{\mathrm{AB}}=16.8, J_{\mathrm{d}}=8.0 \mathrm{~Hz}, 1 \mathrm{H}\right), 3.02\left(\mathrm{~d}\right.$ of $\mathrm{B}$ of $\mathrm{ABq}, J_{\mathrm{AB}}=16.8$, $\left.J_{\mathrm{d}}=4.4 \mathrm{~Hz}, 1 \mathrm{H}\right), 3.17-3.48(\mathrm{~m}, 1 \mathrm{H}), 3.45-3.59(\mathrm{~m}, 3 \mathrm{H}), 3.66(\mathrm{~s}$, $3 \mathrm{H}), 4.99(\mathrm{dd}, J=8.0,4.4 \mathrm{~Hz}, 1 \mathrm{H}), 5.26(\mathrm{~s}, 1 \mathrm{H}), 6.18-6.23(\mathrm{~m}$, 2H), 6.72 (br s, 1H) ppm; (minor) $\delta=2.31$ (br s, 1H), 3.17-3.38 (m, 3H), 3.45-3.58 (m, 3H), 3.67 (s, 3H), 4.91 (dd, $J=5.2,4.8 \mathrm{~Hz}$, $1 \mathrm{H}), 5.23(\mathrm{~s}, 1 \mathrm{H}), 6.22-6.27(\mathrm{~m}, 2 \mathrm{H}), 6.62$ (br s, $1 \mathrm{H}) \mathrm{ppm} ;{ }^{13} \mathrm{C}-$ NMR (major) $\delta=38.9,44.0,44.8,52.0,56.1,70.0,104.1$, 109.5, 119.1, 124.7, 163.7, $169.9 \mathrm{ppm}$; (minor) $\delta=35.1$, 44.3, 44.8, 51.9, 54.5, 70.0, 104.7, 109.3, 116.8, 125.1, 163.7, 170.5 ppm; IR (KBr) $\nu=3287,2999,2941,2878,1734,1653$, 1461, 1438, 1376, 1330, 1307, 1214, 1173, 1118, 1072, 909, 750, $725 \mathrm{~cm}^{-1}$; HRMS (ESI) calcd for $\mathrm{C}_{12} \mathrm{H}_{16} \mathrm{~N}_{3} \mathrm{O}_{3}[\mathrm{M}+1]^{+} 250.1186$, found 250.1188 .

(6S)-6-(2-(Methylthio)ethyl)-1,2,3,10 b-tetrahydroimidazo[1,2a]pyrrolo[2,1-c]pyrazin-5(6H)-one (7h). The reaction of methyl (S)-2-(2-formyl-1H-pyrrol-1-yl)-4-(methylthio)butanoate (1.00 g, $4.18 \mathrm{mmol}$ ) and ethane-1,2-diamine (251 $\mathrm{mg}, 4.18$ $\mathrm{mmol})$ in $\mathrm{MeOH}(10 \mathrm{~mL})$ at $70{ }^{\circ} \mathrm{C}$ for $1 \mathrm{~h}$ produced $7 \mathrm{~h}(914 \mathrm{mg}$, $3.64 \mathrm{mmol}$ ) in $87 \%$ yield as white solid after purification by $\mathrm{SiO}_{2}$ column chromatography.

Data for $7 \boldsymbol{h} .{ }^{1} \mathrm{H}-\mathrm{NMR} \delta=2.00-2.11(\mathrm{~m}, 1 \mathrm{H}), 2.07$ (s, 3H), 2.15$2.25(\mathrm{~m}, 1 \mathrm{H}), 2.38-2.46(\mathrm{~m}, 1 \mathrm{H}), 2.50-2.58(\mathrm{~m}, 1 \mathrm{H}), 3.14-3.24$ $(\mathrm{m}, 1 \mathrm{H}), 3.42-3.52(\mathrm{~m}, 3 \mathrm{H}), 4.71(\mathrm{dd}, J=8.0,5.2 \mathrm{~Hz}, 1 \mathrm{H}), 5.20(\mathrm{~s}$, $1 \mathrm{H}), 6.17-6.21(\mathrm{~m}, 2 \mathrm{H}), 6.67$ (dd, $J=2.8,1.6 \mathrm{~Hz}, 1 \mathrm{H}) \mathrm{ppm} ;{ }^{13} \mathrm{C}-$ NMR $\delta=14.7,29.1,33.6,43.7,44.6,58.5$, 69.7, 103.7, 108.9, 118.7, 124.6, $164.6 \mathrm{ppm}$; IR (KBr) $\nu=3272,3108,2959,2922$, 2885, 2851, 1643, 1454, 1412, 1335, 1298, 1220, 1159, 1156, 1073, 948, 923, 897, 761, $708 \mathrm{~cm}^{-1}$; HRMS (ESI) calcd for $\mathrm{C}_{12} \mathrm{H}_{18} \mathrm{~N}_{3} \mathrm{OS}[\mathrm{M}+1]^{+}$252.1165, found 252.1168.

General procedure for cyclization of pyrralines 5 with $(S)$-2aminopropan-1-ol

(3S)-3-Methyl-2,3-dihydro-10bH-oxazolo[3,2-a]pyrrolo[2,1-c] pyrazin-5(6H)-one (8a). The mixture of methyl 2-(2-formyl-1 $H$ pyrrol-1-yl)acetate (5a) (1.12 g, $6.70 \mathrm{mmol})$ and $(S)$-2aminopropan-1-ol $(0.52 \mathrm{~mL}, 6.70 \mathrm{mmol})$ in toluene $(5 \mathrm{~mL})$ was stirred at room temperature for $2.5 \mathrm{~h}$ and then heated at $110{ }^{\circ} \mathrm{C}$ for $6 \mathrm{~h}$. The reaction mixture was cooled to room temperature, concentrated under reduced pressure, and purified by $\mathrm{SiO}_{2}$ flash column chromatography to give $\mathbf{8 a}(154 \mathrm{mg}, 0.80 \mathrm{mmol})$ in $12 \%$ yield as light-yellow liquid.

Data for 8a. ${ }^{1} \mathrm{H}-\mathrm{NMR} \delta=1.41(\mathrm{~d}, J=6.0 \mathrm{~Hz}, 3 \mathrm{H}), 3.63$ (ddd, $J$ $=6.8,6.4,1.2 \mathrm{~Hz}, 1 \mathrm{H}), 4.40(\mathrm{dd}, J=7.2,6.8 \mathrm{~Hz}, 1 \mathrm{H}), 4.44\left(\mathrm{ddq}, J_{\mathrm{d}}\right.$ $\left.=7.2,6.4, J_{\mathrm{q}}=6.0 \mathrm{~Hz}, 1 \mathrm{H}\right), 4.60\left(\mathrm{~A}\right.$ of $\left.\mathrm{ABq}, J_{\mathrm{AB}}=16.8 \mathrm{~Hz}, 1 \mathrm{H}\right)$, 4.65 (d of $\mathrm{B}$ of $\left.\mathrm{ABq}, J_{\mathrm{AB}}=16.8, J_{\mathrm{d}}=0.8 \mathrm{~Hz}, 1 \mathrm{H}\right), 5.88(\mathrm{br} \mathrm{s}, 1 \mathrm{H})$, $6.29(\mathrm{dd}, J=4.0,2.4 \mathrm{~Hz}, 1 \mathrm{H}), 6.33$ (ddd, $J=4.0,1.6,0.8 \mathrm{~Hz}, 1 \mathrm{H}$ ), $6.64(\mathrm{dd}, J=2.4,1.6 \mathrm{~Hz}, 1 \mathrm{H}) \mathrm{ppm} ;{ }^{13} \mathrm{C}-\mathrm{NMR} \delta=18.0,48.5,51.0$, $72.2,81.7,106.2,110.3,119.1,122.2,162.7 \mathrm{ppm}$; IR (neat) $\nu=$ 2928, 2870, 1712, 1660, 1542, 1463, 1428, 1345, 1310, 1229, 
1168, 1075, 1046, 976, 747, $720 \mathrm{~cm}^{-1}$; HRMS (ESI) calcd for $\mathrm{C}_{10} \mathrm{H}_{12} \mathrm{~N}_{2} \mathrm{O}_{2}+\mathrm{Na}, 215.0791$, found 215.0791.

(3S,6S)-3,6-Dimethyl-2,3-dihydro-10bH-oxazolo[3,2-a]pyrrolo [2,1-c]pyrazin-5(6H)-one (8b). The reaction of methyl $(S)-2-(2-$ formyl-1 $H$-pyrrol-1-yl)propanoate (5b) (1.12 g, $6.19 \mathrm{mmol}$ ) and $(S)$-2-aminopropan-1-ol $(0.49 \mathrm{~mL}, 6.19 \mathrm{mmol})$ in toluene $(5 \mathrm{~mL})$ at room temperature for $2.5 \mathrm{~h}$ and then at $110{ }^{\circ} \mathrm{C}$ for $6 \mathrm{~h}$ produced $8 \mathrm{~b}(523 \mathrm{mg}, 2.53 \mathrm{mmol})$ in $41 \%$ yield as light-yellow liquid after purification by $\mathrm{SiO}_{2}$ column chromatography.

Data for $8 \boldsymbol{b} .{ }^{1} \mathrm{H}-\mathrm{NMR} \delta=1.39(\mathrm{~d}, J=6.8 \mathrm{~Hz}, 3 \mathrm{H}), 1.63(\mathrm{~d}, J=$ $6.8 \mathrm{~Hz}, 3 \mathrm{H}), 3.59-3.67(\mathrm{~m}, 1 \mathrm{H}), 4.34-4.44(\mathrm{~m}, 2 \mathrm{H}), 4.67$ (q, $J=$ $6.8 \mathrm{~Hz}, 1 \mathrm{H}), 5.79$ (br s, $1 \mathrm{H}), 6.26-6.31(\mathrm{~m}, 2 \mathrm{H}), 6.60(\mathrm{dd}, J=2.4$, $2.0 \mathrm{~Hz}, 1 \mathrm{H}) \mathrm{ppm} ;{ }^{13} \mathrm{C}-\mathrm{NMR} \delta=16.3,17.9,51.4,53.5,72.1,81.5$, 106.3, 110.0, 117.7, 122.9, 165.7 ppm; IR (neat) $\nu=3129,2989$, 2931, 2872, 1714, 1655, 1539, 1460, 1422, 1367, 1302, 1206, 1176, 1142, 1018, 978, 920, 820, 746, $719 \mathrm{~cm}^{-1}$; HRMS (ESI) calcd for $\mathrm{C}_{11} \mathrm{H}_{14} \mathrm{~N}_{2} \mathrm{O}_{2}+\mathrm{Na}, 229.0947$, found 229.0952.

$(3 S, 6 S)-6-I s o p r o p y l-3-m e t h y l-2,3-d i h y d r o-10 b H$-oxazolo[3,2a]pyrrolo[2,1-c]pyrazin-5(6H)-one (8c). The reaction of methyl $(S)$-2-(2-formyl-1H-pyrrol-1-yl)-3-methylbutanoate (5c) (1.12 g, $5.36 \mathrm{mmol})$ and $(S)$-2-aminopropan-1-ol (0.42 mL, $5.36 \mathrm{mmol})$ in toluene $(5 \mathrm{~mL})$ at room temperature for $2.5 \mathrm{~h}$ and then at $110{ }^{\circ} \mathrm{C}$ for $6 \mathrm{~h}$ produced $8 \mathrm{c}(917 \mathrm{mg}, 3.91 \mathrm{mmol})$ in $73 \%$ yield as lightyellow liquid after purification by $\mathrm{SiO}_{2}$ column chromatography.

Data for $8 c .{ }^{1} \mathrm{H}-\mathrm{NMR} \delta=0.92(\mathrm{~d}, J=6.8 \mathrm{~Hz}, 3 \mathrm{H}), 1.10(\mathrm{~d}, J=$ $6.8 \mathrm{~Hz}, 3 \mathrm{H}), 1.40(\mathrm{~d}, J=6.0 \mathrm{~Hz}, 3 \mathrm{H}), 2.27$ (m, 1H), 3.60-3.68 (m, $1 \mathrm{H}), 4.33-4.43(\mathrm{~m}, 3 \mathrm{H}), 5.80(\mathrm{~s}, 1 \mathrm{H}), 6.26(\mathrm{dd}, J=4.0,2.8 \mathrm{~Hz}, 1 \mathrm{H})$, 6.30 (ddd, $J=4.0,1.6,0.8 \mathrm{~Hz}, 1 \mathrm{H}), 6.62(\mathrm{dd}, J=2.8,1.6 \mathrm{~Hz}$, 1H) ppm; ${ }^{13} \mathrm{C}-\mathrm{NMR} \delta=17.8,18.0,19.3,34.9,51.1,65.8,72.3,82.1$, 105.2, 109.4, 119.7, 123.8, 165.0 ppm; IR (neat) $\nu=3116,2963$, 2920, 2857, 1714, 1666, 1564, 1449, 1417, 1381, 1370, 1301, 1229, 1197, 1100, 1057, 973, 867, 814, 766, $703 \mathrm{~cm}^{-1}$; HRMS (ESI) calcd for $\mathrm{C}_{13} \mathrm{H}_{18} \mathrm{~N}_{2} \mathrm{O}_{2}+\mathrm{Na} 257.1260$, found 257.1262.

$(3 S, 6 S)-6-((S)-s e c-B u t y l)-3-m e t h y l-2,3-d i h y d r o-10 b H$-oxazolo $[3,2-a]$ pyrrolo[2,1-c]pyrazin-5(6H)-one (8d). The reaction of methyl (2S,3S)-2-(2-formyl-1 $H$-pyrrol-1-yl)-3-methylpentanoate (5e) $(1.12 \mathrm{~g}, 5.02 \mathrm{mmol})$ and $(S)$-2-aminopropan-1-ol $(0.39 \mathrm{~mL}$, $5.02 \mathrm{mmol})$ in toluene $(5 \mathrm{~mL})$ at room temperature for $2.5 \mathrm{~h}$ and then at $110^{\circ} \mathrm{C}$ for $6 \mathrm{~h}$ produced $8 \mathrm{~d}$ ( $959 \mathrm{mg}, 3.86 \mathrm{mmol}$ ) in $77 \%$ yield as light-yellow liquid after purification by $\mathrm{SiO}_{2}$ column chromatography.

Data for $8 \boldsymbol{d}$. ${ }^{1} \mathrm{H}-\mathrm{NMR} \delta=0.90(\mathrm{~d}, J=6.8 \mathrm{~Hz}, 3 \mathrm{H}), 0.93(\mathrm{t}, J=$ $7.6 \mathrm{~Hz}, 3 \mathrm{H}), 1.08-1.20(\mathrm{~m}, 1 \mathrm{H}), 1.38$ (d, $J=6.8 \mathrm{~Hz}, 3 \mathrm{H}), 1.54-1.65$ (m, 1H), 1.91-2.02 (m, 1H), 3.57-3.65 (m, 1H), 4.31-4.40 (m, 2H), 4.51 (d, $J=4.8 \mathrm{~Hz}, 1 \mathrm{H}), 5.79$ (br s, $1 \mathrm{H}), 6.24$ (dd, $J=3.6,2.8 \mathrm{~Hz}$, $1 \mathrm{H}$ ), 6.27 (ddd, $J=3.6,1.6,0.8 \mathrm{~Hz}, 1 \mathrm{H}), 6.61$ (dd, $J=2.8,1.6 \mathrm{~Hz}$, 1H) ppm; ${ }^{13} \mathrm{C}-\mathrm{NMR} \delta=11.4,15.0,17.6,25.0,41.7,50.9,64.3,72.0$, 81.9, 104.9, 109.4, 119.0, 123.6, 164.5 ppm; IR (neat) $\nu=3099$, 2958, 2925, 2867, 1709, 1666, 1563, 1539, 1460, 1430, 1386, 1295, 1216, 1195, 1068, 1055, 978, 871, 817, 766, $708 \mathrm{~cm}^{-1}$; HRMS (ESI) calcd for $\mathrm{C}_{14} \mathrm{H}_{20} \mathrm{~N}_{2} \mathrm{O}_{2}+\mathrm{Na} 271.1417$, found 271.1419.

(3S,6S)-6-Benzyl-3-methyl-2,3-dihydro-10bH-oxazolo[3,2-a] pyrrolo[2,1-c]pyrazin-5(6H)-one (8e). The reaction of methyl $(S)$ 2-(2-formyl-1H-pyrrol-1-yl)-3-phenylpropanoate (5f) (1.12 g, 4.36 $\mathrm{mmol})$ and $(S)$-2-aminopropan-1-ol $(0.34 \mathrm{~mL}, 4.36 \mathrm{mmol})$ in toluene $(5 \mathrm{~mL})$ at room temperature for $2.5 \mathrm{~h}$ and then at $110{ }^{\circ} \mathrm{C}$ for $6 \mathrm{~h}$ produced $8 \mathrm{e}(639 \mathrm{mg}, 2.26 \mathrm{mmol})$ in $52 \%$ yield as lightyellow liquid after purification by $\mathrm{SiO}_{2}$ column chromatography.

Data for $8 e .{ }^{1} \mathrm{H}-\mathrm{NMR} \delta=1.21(\mathrm{~d}, J=6.0 \mathrm{~Hz}, 3 \mathrm{H}), 3.23(\mathrm{dd}, J=$ 13.6, 4.4 Hz, 1H), 3.30-3.37 (m, 2H), 4.18-4.30 (m, 2H), 4.35 (s, $1 \mathrm{H}), 4.93(\mathrm{t}, J=4.4 \mathrm{~Hz}, 1 \mathrm{H}), 6.10(\mathrm{ddd}, J=3.6,1.6,0.8 \mathrm{~Hz}, 1 \mathrm{H})$, $6.31(\mathrm{dd}, J=3.6,2.8 \mathrm{~Hz}, 1 \mathrm{H}), 6.66-6.72(\mathrm{~m}, 3 \mathrm{H}), 7.11-7.16(\mathrm{~m}$, 2H), 7.20-7.25 (m, 1H) ppm; ${ }^{13} \mathrm{C}-\mathrm{NMR} \delta=17.2,41.8,50.6,60.4$, 72.1, 80.8, 104.7, 110.5, 117.6, 124.0, 127.5, 128.0, 129.8, 134.3, $163.8 \mathrm{ppm}$; IR (neat) $\nu=3027,2962,2923,2861,1704,1659$, 1561, 1456, 1437, 1404, 1361, 1311, 1234, 1165, 1077, 1041, 972, 822, 744, $695 \mathrm{~cm}^{-1}$; HRMS (ESI) calcd for $\mathrm{C}_{17} \mathrm{H}_{18} \mathrm{~N}_{2} \mathrm{O}_{2}+\mathrm{Na}$ 305.1260, found 305.1264.

$(3 S, 6 S)-3-M e t h y l-6-p h e n e t h y l-2,3-d i h y d r o-10 b H$-oxazolo[3,2a]pyrrolo[2,1-c]pyrazin-5(6H)-one (8f). The reaction of methyl $(S)$-2-(2-formyl-1H-pyrrol-1-yl)-4-phenylbutanoate $(5 \mathrm{~g})$ (1.12 g, $4.13 \mathrm{mmol})$ and $(S)$-2-aminopropan-1-ol (0.32 mL, $4.13 \mathrm{mmol})$ in toluene $(5 \mathrm{~mL})$ at room temperature for $2.5 \mathrm{~h}$ and then at $110{ }^{\circ} \mathrm{C}$ for $6 \mathrm{~h}$ produced $8 \mathrm{f}(269 \mathrm{mg}, 0.91 \mathrm{mmol})$ in $22 \%$ yield as lightyellow liquid after purification by $\mathrm{SiO}_{2}$ column chromatography.

Data for $8 f .{ }^{1} \mathrm{H}-\mathrm{NMR} \delta=1.37(\mathrm{~d}, J=6.4 \mathrm{~Hz}, 3 \mathrm{H}), 2.24-2.33(\mathrm{~m}$, $2 \mathrm{H}), 2.47-2.55(\mathrm{~m}, 1 \mathrm{H}), 2.60-2.68(\mathrm{~m}, 1 \mathrm{H}), 3.59-3.66(\mathrm{~m}, 1 \mathrm{H})$, $4.35-4.44(\mathrm{~m}, 2 \mathrm{H}), 4.68(\mathrm{t}, J=6.0 \mathrm{~Hz}, 1 \mathrm{H}), 5.78(\mathrm{~s}, 1 \mathrm{H}), 6.30(\mathrm{dd}, J$ $=3.6,2.8 \mathrm{~Hz}, 1 \mathrm{H}), 6.32(\mathrm{ddd}, J=3.6,1.6,0.8 \mathrm{~Hz}, 1 \mathrm{H}), 6.66$ (dd, $J$ $=2.8,1.6 \mathrm{~Hz}, 1 \mathrm{H}), 7.12-7.16(\mathrm{~m}, 2 \mathrm{H}), 7.16-7.22(\mathrm{~m}, 1 \mathrm{H}), 7.24-$ $7.30(\mathrm{~m}, 2 \mathrm{H}) \mathrm{ppm} ;{ }^{13} \mathrm{C}-\mathrm{NMR} \delta=17.8,30.9,37.4,51.1,59.5,72.3$, $81.7,105.7,110.2,118.7,122.9,126.3,128.3,128.5,140.0$, 165.6 ppm; IR (neat) $\nu=3016,2966,2930,2857,1714,1666$, 1561, 1449, 1434, 1406, 1359, 1302, 1227, 1168, 1076, 1058, 977, 826, 766, 725, $693 \mathrm{~cm}^{-1}$; HRMS (ESI) calcd for $\mathrm{C}_{18} \mathrm{H}_{20} \mathrm{~N}_{2} \mathrm{O}_{2}+\mathrm{Na}$, 319.1417 , found 319.1419 .

Methyl 2-((3S,6S)-3-methyl-5-oxo-2,3,5,6-tetrahydro-10bHoxazolo[3,2-a]pyrrolo[2,1-c]pyrazin-6-yl)acetate $(8 \mathrm{~g})$. The reaction of dimethyl $(S)$-2-(2-formyl-1H-pyrrol-1-yl)succinate $(\mathbf{5 h})$ $(1.12 \mathrm{~g}, 4.68 \mathrm{mmol})$ and $(S)$-2-aminopropan-1-ol (0.36 mL, 4.68 $\mathrm{mmol}$ ) in toluene $(5 \mathrm{~mL})$ at room temperature for $2.5 \mathrm{~h}$ and then at $110{ }^{\circ} \mathrm{C}$ for $6 \mathrm{~h}$ produced $8 \mathrm{~g}$ (334 $\left.\mathrm{mg}, 1.26 \mathrm{mmol}\right)$ in $27 \%$ yield (a 1.05 : 1 mixture of stereoisomers) as light-yellow liquid after purification by $\mathrm{SiO}_{2}$ column chromatography.

Data for 8g. ${ }^{1} \mathrm{H}-\mathrm{NMR}$ (major) $\delta=1.42(\mathrm{~d}, J=6.4 \mathrm{~Hz}, 3 \mathrm{H}), 2.97$ (dd, $J=16.4,6.8 \mathrm{~Hz}, 1 \mathrm{H}), 3.06(\mathrm{dd}, J=16.4,4.4 \mathrm{~Hz}, 1 \mathrm{H}), 3.60-$ $3.70(\mathrm{~m}, 1 \mathrm{H}), 3.65(\mathrm{~s}, 3 \mathrm{H}), 4.35-4.46(\mathrm{~m}, 2 \mathrm{H}), 4.99(\mathrm{dd}, J=6.7$, $4.4 \mathrm{~Hz}, 1 \mathrm{H}), 5.82$ (br s, $1 \mathrm{H}), 6.26$ (dd, $J=3.6,1.6 \mathrm{~Hz}, 1 \mathrm{H}), 6.30$ (dd, $J=3.6,2.4 \mathrm{~Hz}, 1 \mathrm{H}$ ), 6.70 (dd, $J=2.4,1.6 \mathrm{~Hz}, 1 \mathrm{H}) \mathrm{ppm}$; (minor) $\delta=1.40(\mathrm{~d}, J=6.4 \mathrm{~Hz}, 3 \mathrm{H}), 3.21(\mathrm{dd}, J=17.2,5.6 \mathrm{~Hz}, 1 \mathrm{H})$, $3.36(\mathrm{dd}, J=17.2,5.6 \mathrm{~Hz}, 1 \mathrm{H}), 3.60-3.70(\mathrm{~m}, 1 \mathrm{H}), 3.71$ (s, 3H), 4.35$4.48(\mathrm{~m}, 2 \mathrm{H}), 5.00(\mathrm{t}, J=5.6 \mathrm{~Hz}, 1 \mathrm{H}), 5.79$ (br s, 1H), 6.27-6.36 (m, $2 \mathrm{H}), 6.64(\mathrm{~m}, 1 \mathrm{H}) \mathrm{ppm} ;{ }^{13} \mathrm{C}-\mathrm{NMR}$ (major) $\delta=17.9,39.5,51.2,52.2$, 54.5, 72.4, 81.5, 106.8, 110.4, 118.8, 122.9, 164.1, 169.9 ppm; (minor) $\delta=17.6,36.2,51.7,52.1,55.8,72.0,81.3,105.8,110.5$, 117.5, 122.7, 164.7, $170.6 \mathrm{ppm}$; IR (neat) $\nu=2957,2926,2856$, 1737, 1671, 1563, 1461, 1442, 1379, 1336, 1310, 1272, 1220, 1203, 1172, 1077, 1055, 976, 914, 776, 733, $673 \mathrm{~cm}^{-1}$; HRMS (ESI) calcd for $\mathrm{C}_{13} \mathrm{H}_{16} \mathrm{~N}_{2} \mathrm{O}_{4}+\mathrm{Na} 287.1002$, found 287.1002.

(3S,6S)-3-Methyl-6-(2-(methylthio)ethyl)-2,3-dihydro-10bHoxazolo[3,2-a]pyrrolo[2,1-c]pyrazin-5(6H)-one $(8 \mathrm{~h})$. The reaction 
of methyl (S)-2-(2-formyl-1 $H$-pyrrol-1-yl)-4-(methylthio) butanoate $(5 \mathbf{j})(1.12 \mathrm{~g}, 4.68 \mathrm{mmol})$ and $(S)$-2-aminopropan-1-ol $(0.36 \mathrm{~mL}, 4.68 \mathrm{mmol})$ in toluene $(5 \mathrm{~mL})$ at room temperature for $2.5 \mathrm{~h}$ and then at $110{ }^{\circ} \mathrm{C}$ for $6 \mathrm{~h}$ produced $8 \mathrm{~h}(299 \mathrm{mg}, 1.12$ $\mathrm{mmol}$ ) in $24 \%$ yield as light-yellow liquid after purification by $\mathrm{SiO}_{2}$ column chromatography.

Data for $8 \boldsymbol{h} .{ }^{1} \mathrm{H}-\mathrm{NMR} \delta=1.40(\mathrm{~d}, J=6.0 \mathrm{~Hz}, 3 \mathrm{H}), 2.09(\mathrm{~s}, 3 \mathrm{H})$, 2.12-2.22 (m, 1H), 2.22-2.31 (m, 1H), 2.33-2.41 (m, 1H), 2.47$2.55(\mathrm{~m}, 1 \mathrm{H}), 3.61-3.69(\mathrm{~m}, 1 \mathrm{H}), 4.34-4.44(\mathrm{~m}, 2 \mathrm{H}), 4.78(\mathrm{dd}, J=$ 6.8, $5.6 \mathrm{~Hz}, 1 \mathrm{H}), 5.80$ (s, 1H), $6.28(\mathrm{dd}, J=4.0,2.8 \mathrm{~Hz}, 1 \mathrm{H}), 6.31$ $(\mathrm{ddd}, J=4.0,1.6,0.8 \mathrm{~Hz}, 1 \mathrm{H}), 6.68(\mathrm{dd}, J=2.8,1.6 \mathrm{~Hz}, 1 \mathrm{H}) \mathrm{ppm}$; ${ }^{13}$ C-NMR $\delta=15.2,17.7,29.2,34.9,51.1,58.6,72.3,81.7,105.8$, 110.2, 118.8, 122.9, $165.4 \mathrm{ppm}$; IR (neat) $\nu=2967,2910,2862$, 1645, 1556, 1465, 1412, 1398, 1354, 1307, 1228, 1168, 1041, 975, 830, 766, $719 \mathrm{~cm}^{-1}$; HRMS (ESI) calcd for $\mathrm{C}_{13} \mathrm{H}_{18} \mathrm{~N}_{2} \mathrm{O}_{2} \mathrm{~S}+\mathrm{Na}$, 289.0981, found 289.0985 .

\section{General procedure for cyclization of pyrralines 5 with $(S)$-2-} amino-3-methylbutan-1-ol (L-valinol)

(3S)-3-Isopropyl-2,3-dihydro-10bH-oxazolo[3,2-a]pyrrolo[2,1c]pyrazin-5(6H)-one (9a). The mixture of methyl 2-(2-formyl- $1 \mathrm{H}$ pyrrol-1-yl)acetate (5a) $(1.12 \mathrm{~g}, 6.70 \mathrm{mmol})$ and L-valinol $(0.69 \mathrm{~g}$, $6.70 \mathrm{mmol})$ in toluene $(5 \mathrm{~mL})$ was stirred at room temperature for $2.5 \mathrm{~h}$ and then heated at $110{ }^{\circ} \mathrm{C}$ for $6 \mathrm{~h}$. The reaction mixture was cooled to room temperature, concentrated under reduced pressure, and purified by $\mathrm{SiO}_{2}$ flash column chromatography to give 9a (59 mg, $0.27 \mathrm{mmol}$ ) in $4 \%$ yield as light-yellow liquid.

Data for 9a. ${ }^{1} \mathrm{H}-\mathrm{NMR} \delta=0.98(\mathrm{~d}, J=6.8 \mathrm{~Hz}, 3 \mathrm{H}), 1.01(\mathrm{~d}, J=$ $6.4 \mathrm{~Hz}, 3 \mathrm{H}), 2.14(\mathrm{~m}, 1 \mathrm{H}), 3.83(\mathrm{dd}, J=8.8,6.8 \mathrm{~Hz}, 1 \mathrm{H}), 4.21$ (dd, $J=8.8,8.0 \mathrm{~Hz}, 1 \mathrm{H}), 4.29$ (ddd, $J=8.0,7.2,6.8 \mathrm{~Hz}, 1 \mathrm{H}$ ), 4.63 (A of $\left.\mathrm{ABq}, J_{\mathrm{AB}}=17.2 \mathrm{~Hz}, 1 \mathrm{H}\right), 4.72\left(\mathrm{~B}\right.$ of $\left.\mathrm{ABq}, J_{\mathrm{AB}}=17.2 \mathrm{~Hz}, 1 \mathrm{H}\right), 5.74$ $(\mathrm{s}, 1 \mathrm{H}), 6.30(\mathrm{dd}, J=3.6,2.4 \mathrm{~Hz}, 1 \mathrm{H}), 6.33(\mathrm{ddd}, J=3.6,1.6$, $0.8 \mathrm{~Hz}, 1 \mathrm{H}), 6.65(\mathrm{dd}, J=2.4,1.6 \mathrm{~Hz}, 1 \mathrm{H}) \mathrm{ppm} ;{ }^{13} \mathrm{C}-\mathrm{NMR} \delta=$ 17.5, 19.2, 30.8, 48.4, 60.2 , 67.7, 82.5, 106.5, 110.4, 119.1, 121.9, 163.9 ppm; IR (neat) $\nu=2952,2929,2872,1666,1561,1460$, 1429, 1367, 1322, 1268, 1227, 1189, 1081, 1048, 973, 870, 825, 761, $713 \mathrm{~cm}^{-1}$; HRMS (ESI) calcd for $\mathrm{C}_{12} \mathrm{H}_{16} \mathrm{~N}_{2} \mathrm{O}_{2}+\mathrm{Na}$, 243.1104, found 243.1107.

$(3 S, 6 S)$-3-Isopropyl-6-methyl-2,3-dihydro-10bH-oxazolo[3,2a]pyrrolo[2,1-c]pyrazin-5(6H)-one (9b). The reaction of methyl $(S)$-2-(2-formyl-1 $H$-pyrrol-1-yl)propanoate $\quad(5 \mathbf{b}) \quad(1.12$ g, 6.19 $\mathrm{mmol})$ and $\mathrm{L}$-valinol $(0.64 \mathrm{~g}, 6.19 \mathrm{mmol})$ in toluene $(5 \mathrm{~mL})$ at room temperature for $2.5 \mathrm{~h}$ and then at $110^{\circ} \mathrm{C}$ for $6 \mathrm{~h}$ produced 9b (392 mg, $1.67 \mathrm{mmol}$ ) in 27\% yield as light-yellow liquid after purification by $\mathrm{SiO}_{2}$ column chromatography.

Data for 9b. ${ }^{1} \mathrm{H}-\mathrm{NMR} \delta=0.97(\mathrm{~d}, J=7.2 \mathrm{~Hz}, 3 \mathrm{H}), 1.01(\mathrm{~d}, J=$ $6.8 \mathrm{~Hz}, 3 \mathrm{H}), 1.79(\mathrm{~d}, J=7.2 \mathrm{~Hz}, 3 \mathrm{H}), 2.11(\mathrm{~m}, 1 \mathrm{H}), 3.83(\mathrm{dd}, J=$ $8.8,6.8 \mathrm{~Hz}, 1 \mathrm{H}), 4.17$ (dd, $J=8.8,7.6 \mathrm{~Hz}, 1 \mathrm{H}$ ), 4.26 (ddd, $J=8.0$, $7.6,6.8 \mathrm{~Hz}, 1 \mathrm{H}), 4.68(\mathrm{q}, J=7.2 \mathrm{~Hz}, 1 \mathrm{H}), 5.74(\mathrm{~s}, 1 \mathrm{H}), 6.30(\mathrm{dd}, J=$ $3.6,2.8 \mathrm{~Hz}, 1 \mathrm{H}), 6.33(\mathrm{ddd}, J=3.6,1.6,0.8 \mathrm{~Hz}, 1 \mathrm{H}), 6.76$ (dd, $J=$ $2.8,1.6 \mathrm{~Hz}, 1 \mathrm{H}) \mathrm{ppm} ;{ }^{13} \mathrm{C}-\mathrm{NMR} \delta=17.2,17.7,19.3,30.8,53.4,60.7$, 67.6, 82.2, 106.6, 110.1, 117.9, 122.4, $167.1 \mathrm{ppm}$; IR (neat) $\nu=2958$, 2942, 2872, 1703, 1661, 1562, 1544, 1460, 1422, 1365, 1301, 1216, 1111, 1085, 1058, 984, 950, 857, 825, 751, $708 \mathrm{~cm}^{-1}$; HRMS (ESI) calcd for $\mathrm{C}_{13} \mathrm{H}_{18} \mathrm{~N}_{2} \mathrm{O}_{2}+\mathrm{Na}, 257.1260$, found 257.1263.
$(3 S, 6 S)-3,6-D i i s o p r o p y l-2,3-d i h y d r o-10 b H-o x a z o l o[3,2-a] p y r-$ rolo[2,1-c]pyrazin-5(6H)-one (9c). The reaction of methyl $(S)$-2(2-formyl-1 $H$-pyrrol-1-yl)-3-methylbutanoate (5c) (1.12 g, 5.36 $\mathrm{mmol})$ and $\mathrm{L}$-valinol $(0.55 \mathrm{~g}, 5.36 \mathrm{mmol})$ in toluene $(5 \mathrm{~mL})$ at room temperature for $2.5 \mathrm{~h}$ and then at $110{ }^{\circ} \mathrm{C}$ for $6 \mathrm{~h}$ produced 9c (858 mg, $3.27 \mathrm{mmol}$ ) in 61\% yield as light-yellow liquid after purification by $\mathrm{SiO}_{2}$ column chromatography.

Data for $9 c .{ }^{1} \mathrm{H}-\mathrm{NMR} \delta=0.95(\mathrm{~d}, J=6.8 \mathrm{~Hz}, 3 \mathrm{H}), 0.99(\mathrm{~d}, J=$ $7.2 \mathrm{~Hz}, 3 \mathrm{H}$ ), 1.02 (d, $J=6.8 \mathrm{~Hz}, 3 \mathrm{H}), 1.03$ (d, $J=6.8 \mathrm{~Hz}, 3 \mathrm{H})$, $2.17-2.33$ (m, 2H), 3.86 (dd, $J=8.8,6.8 \mathrm{~Hz}, 1 \mathrm{H}), 4.17$ (dd, $J=8.8$, $7.6 \mathrm{~Hz}, 1 \mathrm{H}), 4.28$ (ddd, $J=7.6,7.2,6.8 \mathrm{~Hz}, 1 \mathrm{H}), 4.46(\mathrm{~d}, J=$ $5.2 \mathrm{~Hz}, 1 \mathrm{H}), 5.77$ (s, 1H), 6.26 (dd, $J=3.6,2.8 \mathrm{~Hz}, 1 \mathrm{H}), 6.28$ (ddd, $J=3.6,1.6,0.8 \mathrm{~Hz}, 1 \mathrm{H}), 6.63(\mathrm{dd}, J=2.8,1.6 \mathrm{~Hz}, 1 \mathrm{H}) \mathrm{ppm} ;{ }^{13} \mathrm{C}-$ NMR $\delta=17.5,18.2,19.2,19.2,30.3,35.0,60.1,65.9,67.2,83.0$, 105.2, 109.5, 119.4, 123.8, 165.9 ppm; IR (neat) $\nu=3100,2958$, 2857, 1702, 1661, 1561, 1455, 1429, 1396, 1375, 1306, 1227, 1189, 1105, 1058, 967, 867, 825, 765, $708 \mathrm{~cm}^{-1}$; HRMS (ESI) calcd for $\mathrm{C}_{15} \mathrm{H}_{22} \mathrm{~N}_{2} \mathrm{O}_{2}+\mathrm{Na}, 285.1573$, found 285.1575.

(3S,6S)-6-((S)-sec-Butyl)-3-isopropyl-2,3-dihydro-10bH-oxazolo[3,2-a]pyrrolo[2,1-c]pyrazin-5(6H)-one (9d). The reaction of methyl (2S,3S)-2-(2-formyl-1 $H$-pyrrol-1-yl)-3-methylpentanoate (5e) $(1.12 \mathrm{~g}, 5.02 \mathrm{mmol})$ and L-valinol $(0.52 \mathrm{~g}, 5.02 \mathrm{mmol})$ in toluene (5 $\mathrm{mL}$ ) at room temperature for $2.5 \mathrm{~h}$ and then at $110{ }^{\circ} \mathrm{C}$ for $6 \mathrm{~h}$ produced 9d (694 mg, $2.51 \mathrm{mmol}$ ) in 50\% yield as light-yellow liquid after purification by $\mathrm{SiO}_{2}$ column chromatography.

Data for 9d. ${ }^{1} \mathrm{H}-\mathrm{NMR} \delta=0.90(\mathrm{~d}, J=7.2 \mathrm{~Hz}, 3 \mathrm{H}), 0.95(\mathrm{t}, J=$ $7.6 \mathrm{~Hz}, 3 \mathrm{H}), 0.98(\mathrm{~d}, J=6.0 \mathrm{~Hz}, 3 \mathrm{H}), 1.00(\mathrm{~d}, J=6.8 \mathrm{~Hz}, 3 \mathrm{H})$, 1.08-2.22 (m, 1H), 1.57-1.68 (m, 1H), 1.93-2.03 (m, 1H), 2.14-2.26 $(\mathrm{m}, 1 \mathrm{H}), 3.85$ (dd, $J=8.8,6.8 \mathrm{~Hz}, 1 \mathrm{H}), 4.17$ (dd, $J=8.8,7.6 \mathrm{~Hz}, 1 \mathrm{H})$, 4.28 (ddd, $J=7.6,7.2,6.8 \mathrm{~Hz}, 1 \mathrm{H}), 4.56(\mathrm{~d}, J=5.2 \mathrm{~Hz}, 1 \mathrm{H}), 5.77$ (s, $1 \mathrm{H}), 6.26-6.28(\mathrm{~m}, 2 \mathrm{H}), 6.63(\mathrm{dd}, J=2.8,1.6 \mathrm{~Hz}, 1 \mathrm{H}) \mathrm{ppm} ;{ }^{13} \mathrm{C}-\mathrm{NMR}$ $\delta=11.6$, 15.2, 17.6, 19.2, 25.4, 30.4, 42.0, 60.2, 64.6, 67.3, 83.0, 105.2, 109.7, 119.0, 123.8, 165.6 ppm; IR (neat) $\nu=2958,2939$, 2878, 1709, 1655, 1568, 1544, 1460, 1431, 1381, 1295, 1232, 1200, 1077, 1058, 967, 879, 833, 766, $713 \mathrm{~cm}^{-1}$; HRMS (ESI) calcd for $\mathrm{C}_{16} \mathrm{H}_{24} \mathrm{~N}_{2} \mathrm{O}_{2}+\mathrm{Na}, 299.1730$, found 299.1734.

(3S,6S)-6-Benzyl-3-isopropyl-2,3-dihydro-10bH-oxazolo[3,2-a] pyrrolo[2,1-c]pyrazin-5(6H)-one (9e). The reaction of methyl $(S)$ 2-(2-formyl-1H-pyrrol-1-yl)-3-phenylpropanoate (5f) (1.12 g, 4.36 $\mathrm{mmol})$ and $\mathrm{L}$-valinol $(0.45 \mathrm{~g}, 4.36 \mathrm{mmol})$ in toluene $(5 \mathrm{~mL})$ at room temperature for $2.5 \mathrm{~h}$ and then at $110{ }^{\circ} \mathrm{C}$ for $6 \mathrm{~h}$ produced 9e (961 mg, $3.10 \mathrm{mmol}$ ) in 71\% yield as light-yellow liquid after purification by $\mathrm{SiO}_{2}$ column chromatography.

Data for $9 e .{ }^{1} \mathrm{H}-\mathrm{NMR} \delta=0.76(\mathrm{~d}, J=7.2 \mathrm{~Hz}, 3 \mathrm{H}), 0.88(\mathrm{~d}, J=$ $6.8 \mathrm{~Hz}, 3 \mathrm{H}), 2.09(\mathrm{~m}, 1 \mathrm{H}), 3.29\left(\mathrm{~d}\right.$ of $\mathrm{A}$ of $\mathrm{ABq}, J_{\mathrm{AB}}=13.6, J_{\mathrm{d}}=$ $4.8 \mathrm{~Hz}, 1 \mathrm{H}), 3.34\left(\mathrm{~d}\right.$ of $\mathrm{B}$ of $\left.\mathrm{ABq}, J_{\mathrm{AB}}=13.6, J_{\mathrm{d}}=4.4 \mathrm{~Hz}, 1 \mathrm{H}\right), 3.68$ (dd, $J=8.8,6.8 \mathrm{~Hz}, 1 \mathrm{H}), 4.04$ (dd, $J=8.8,7.6 \mathrm{~Hz}, 1 \mathrm{H}$ ), 4.17 (ddd, $J=7.6,7.2,6.8 \mathrm{~Hz}, 1 \mathrm{H}), 4.86(\mathrm{~s}, 1 \mathrm{H}), 4.96(\mathrm{t}, J=4.8 \mathrm{~Hz}, 1 \mathrm{H}), 6.16$ $(\mathrm{ddd}, J=3.6,1.6,0.8 \mathrm{~Hz}, 1 \mathrm{H}), 6.31$ (dd, $J=3.6,2.8 \mathrm{~Hz}, 1 \mathrm{H}), 6.64$ $(\mathrm{dd}, J=2.8,1.6 \mathrm{~Hz}, 1 \mathrm{H}), 6.66-6.70(\mathrm{~m}, 2 \mathrm{H}), 7.12-7.23(\mathrm{~m}$, $3 \mathrm{H}) \mathrm{ppm} ;{ }^{13} \mathrm{C}-\mathrm{NMR} \delta=17.1,19.0,30.0,41.6,60.2,60.6,66.6$, 82.2 , 105.1, 110.4, 117.7, 123.6, 127.2, 128.2, 129.4, 134.5, 165.3 ppm; IR (neat) $\nu=3032,2962,2926,2872,1708,1661$, 1556, 1455, 1430, 1403, 1350, 1306, 1297, 1237, 1175, 1113, 1079, 1041, 967, 853, 816, 729, $693 \mathrm{~cm}^{-1}$; HRMS (ESI) calcd for $\mathrm{C}_{19} \mathrm{H}_{22} \mathrm{~N}_{2} \mathrm{O}_{2}+\mathrm{Na}, 333.1573$, found 333.1575. 
(3S,6S)-3-Isopropyl-6-phenethyl-2,3-dihydro-10bH-oxazolo $[3,2-a]$ pyrrolo[2,1-c]pyrazin-5(6H)-one (9f). The reaction of methyl (S)-2-(2-formyl-1 $H$-pyrrol-1-yl)-4-phenylbutanoate (5g) $(1.12 \mathrm{~g}, 4.13 \mathrm{mmol})$ and L-valinol $(0.43 \mathrm{~g}, 4.13 \mathrm{mmol})$ in toluene $(5 \mathrm{~mL})$ at room temperature for $2.5 \mathrm{~h}$ and then at $110{ }^{\circ} \mathrm{C}$ for $6 \mathrm{~h}$ produced 9 f (683 $\mathrm{mg}, 2.11 \mathrm{mmol}$ ) in 51\% yield as light-yellow liquid after purification by $\mathrm{SiO}_{2}$ column chromatography.

Data for 9f. ${ }^{1} \mathrm{H}-\mathrm{NMR} \delta=0.99(\mathrm{~d}, J=7.2 \mathrm{~Hz}, 3 \mathrm{H}), 1.02(\mathrm{~d}, J=$ $7.2 \mathrm{~Hz}, 3 \mathrm{H}), 2.19(\mathrm{~m}, 1 \mathrm{H}), 2.25-2.32(\mathrm{~m}, 2 \mathrm{H}), 2.41-2.50(\mathrm{~m}, 1 \mathrm{H})$, 2.63-2.72 (m, 1H), 3.86 (dd, $J=8.8,6.8 \mathrm{~Hz}, 1 \mathrm{H}), 4.20$ (dd, $J=8.8$, $7.6 \mathrm{~Hz}, 1 \mathrm{H}), 4.30$ (ddd, $J=7.6,7.2,6.8 \mathrm{~Hz}, 1 \mathrm{H}), 4.71(\mathrm{t}, J=$ $5.6 \mathrm{~Hz}, 1 \mathrm{H}), 5.79(\mathrm{~s}, 1 \mathrm{H}), 6.29-6.33(\mathrm{~m}, 2 \mathrm{H}), 6.63(\mathrm{dd}, J=2.4$, $1.6 \mathrm{~Hz}, 1 \mathrm{H}), 7.11-7.15(\mathrm{~m}, 2 \mathrm{H}), 7.16-7.22(\mathrm{~m}, 1 \mathrm{H}), 7.24-7.30$ (m, $2 \mathrm{H}) \mathrm{ppm} ;{ }^{13} \mathrm{C}-\mathrm{NMR} \delta=17.5,19.2$, 30.6, 31.0, 38.0, 59.6, 60.1, 67.6, 82.6, 105.9, 110.3, 118.6, 122.8, 126.3, 128.3, 128.5, 140.1, 166.6 ppm; IR (neat) $\nu=3015,2963,2925,2878,1709,1666$, 1549, 1455, 1422, 1403, 1343, 1302, 1232, 1158, 1058, 983, 876, 828, 713, $698 \mathrm{~cm}^{-1}$; HRMS (ESI) calcd for $\mathrm{C}_{20} \mathrm{H}_{24} \mathrm{~N}_{2} \mathrm{O}_{2}+\mathrm{Na}$, 347.1730, found 347.1732.

Methyl 2-((3S,6S)-3-isopropyl-5-oxo-2,3,5,6-tetrahydro-10bHoxazolo[3,2-a]pyrrolo[2,1-c]pyrazin-6-yl)acetate (9g). The reaction of dimethyl $(S)$-2-(2-formyl-1H-pyrrol-1-yl)succinate $(\mathbf{5 h})$ $(1.12 \mathrm{~g}, 4.68 \mathrm{mmol})$ and L-valinol $(0.48 \mathrm{~g}, 4.69 \mathrm{mmol})$ in toluene $(5 \mathrm{~mL})$ at room temperature for $2.5 \mathrm{~h}$ and then at $110{ }^{\circ} \mathrm{C}$ for $6 \mathrm{~h}$ produced $9 \mathrm{~g}$ (137 $\mathrm{mg}, 0.47 \mathrm{mmol}$ ) in 10\% yield as light-yellow liquid after purification by $\mathrm{SiO}_{2}$ column chromatography.

Data for $9 g .{ }^{1} \mathrm{H}-\mathrm{NMR} \delta=0.99(\mathrm{~d}, J=6.8 \mathrm{~Hz}, 3 \mathrm{H}), 0.99(\mathrm{~d}, J=$ $7.2 \mathrm{~Hz}, 3 \mathrm{H}), 2.26(\mathrm{~m}, 1 \mathrm{H}), 3.00\left(\mathrm{~d}\right.$ of A of ABq, $J_{\mathrm{AB}}=16.4, J_{\mathrm{d}}=$ $6.8 \mathrm{~Hz}, 1 \mathrm{H}$ ), 3.08 (d of B of ABq, $J_{\mathrm{AB}}=16.4, J_{\mathrm{d}}=4.4 \mathrm{~Hz}, 1 \mathrm{H}$ ), 3.65 (s, 3H), $3.89(\mathrm{dd}, J=8.0,6.0 \mathrm{~Hz}, 1 \mathrm{H}), 4.21(\mathrm{dd}, J=8.0,7.6 \mathrm{~Hz}$, $1 \mathrm{H}), 4.26$ (ddd, $J=7.6,6.8,6.0 \mathrm{~Hz}, 1 \mathrm{H}), 5.01$ (dd, $J=6.4,4.4 \mathrm{~Hz}$, $1 \mathrm{H}), 5.79(\mathrm{~s}, 1 \mathrm{H}), 6.27(\mathrm{dd}, J=4.0,2.8 \mathrm{~Hz}, 1 \mathrm{H}), 6.29$ (ddd, $J=4.0$, $1.6,0.8 \mathrm{~Hz}, 1 \mathrm{H}), 6.70(\mathrm{dd}, J=2.8,1.6 \mathrm{~Hz}, 1 \mathrm{H}) \mathrm{ppm} ;{ }^{13} \mathrm{C}-\mathrm{NMR} \delta=$ 17.2, 19.0, 30.4, 39.7, 52.1, 55.9, 60.3, 67.5, 82.5, 106.0, 110.5, 118.6, 122.8, 165.0, $169.8 \mathrm{ppm}$; IR (neat) $\nu=2958,2931,2862$, 1740, 1655, 1570, 1449, 1439, 1399, 1371, 1317, 1237, 1191, 1168, 1063, 978, 862, 822, 772, $713 \mathrm{~cm}^{-1}$; HRMS (ESI) calcd for $\mathrm{C}_{15} \mathrm{H}_{20} \mathrm{~N}_{2} \mathrm{O}_{4}+\mathrm{Na}, 315.1315$, found 315.1316.

(3S,6S)-3-isopropyl-6-(2-(methylthio)ethyl)-2,3-dihydro$10 b H$-oxazolo[3,2-a]pyrrolo[2,1-c]pyrazin-5(6H)-one (9h). The reaction of methyl $(S)$-2-(2-formyl- $1 H$-pyrrol-1-yl)-4-(methylthio) butanoate $(5 \mathbf{j})(1.12 \mathrm{~g}, 4.68 \mathrm{mmol})$ and L-valinol $(0.48 \mathrm{~g}, 4.65$ $\mathrm{mmol})$ in toluene $(5 \mathrm{~mL})$ at room temperature for $2.5 \mathrm{~h}$ and then at $110{ }^{\circ} \mathrm{C}$ for $6 \mathrm{~h}$ produced $9 \mathrm{~h}(331 \mathrm{mg}, 1.12 \mathrm{mmol})$ in $24 \%$ yield as light-yellow liquid after purification by $\mathrm{SiO}_{2}$ column chromatography.

Data for $9 \boldsymbol{h} .{ }^{1} \mathrm{H}-\mathrm{NMR} \delta=0.96(\mathrm{~d}, J=6.8 \mathrm{~Hz}, 3 \mathrm{H}), 0.97(\mathrm{~d}, J=$ $6.8 \mathrm{~Hz}, 3 \mathrm{H}), 2.06(\mathrm{~s}, 3 \mathrm{H}), 2.13-2.36(\mathrm{~m}, 4 \mathrm{H}), 2.46-2.55(\mathrm{~m}, 1 \mathrm{H})$, $3.84(\mathrm{dd}, J=8.8,6.8 \mathrm{~Hz}, 1 \mathrm{H}), 4.17$ (dd, $J=8.8,7.6 \mathrm{~Hz}, 1 \mathrm{H}), 4.25$ $(\mathrm{ddd}, J=7.6,7.2,6.8 \mathrm{~Hz}, 1 \mathrm{H}), 4.78(\mathrm{dd}, J=6.4,5.6 \mathrm{~Hz}, 1 \mathrm{H}), 5.74$ $(\mathrm{s}, 1 \mathrm{H}), 6.26(\mathrm{dd}, J=4.0,2.8 \mathrm{~Hz}, 1 \mathrm{H}), 6.28(\mathrm{ddd}, J=4.0,1.6$, $0.8 \mathrm{~Hz}, 1 \mathrm{H}), 6.67(\mathrm{dd}, J=2.8,1.6 \mathrm{~Hz}, 1 \mathrm{H}) \mathrm{ppm} ;{ }^{13} \mathrm{C}-\mathrm{NMR} \delta=$ 15.3, 17.5, 19.2, 29.2, 30.5, 35.3, 58.7, 60.1, 67.5, 82.6, 106.0, 110.3, 118.7, 122.8, 166.4 ppm; IR (neat) $\nu=2958,2910,2872$, 1703, 1661, 1550, 1544, 1449, 1422, 1406, 1345, 1307, 1237,
1163, 1114, 1053, 978, 870, 831, 777, $715 \mathrm{~cm}^{-1}$; HRMS (ESI) calcd for $\mathrm{C}_{15} \mathrm{H}_{22} \mathrm{~N}_{2} \mathrm{O}_{2} \mathrm{~S}+\mathrm{Na}, 317.1294$, found 317.1296.

General procedure for cyclization of pyrralines 5 with $(S)-2-$ amino-2-phenylethan-1-ol (1-phenylalaninol)

(3S)-3-Benzyl-2,3-dihydro-10bH-oxazolo[3,2-a]pyrrolo[2,1-c] pyrazin-5(6H)-one (10a). The mixture of methyl 2-(2-formyl-1 $H^{-}$ pyrrol-1-yl)acetate (5a) $(1.12 \mathrm{~g}, 6.70 \mathrm{mmol})$ and L-phenylalaninol $(1.01 \mathrm{~g}, 6.70 \mathrm{mmol})$ in toluene $(5 \mathrm{~mL})$ was stirred at room temperature for $2.5 \mathrm{~h}$ and then heated at $110{ }^{\circ} \mathrm{C}$ for $6 \mathrm{~h}$. The reaction mixture was cooled to room temperature, concentrated under reduced pressure, and purified by $\mathrm{SiO}_{2}$ flash column chromatography to give $10 a(108 \mathrm{mg}, 0.40 \mathrm{mmol})$ in $6 \%$ yield as light-yellow liquid.

Data for 10a. ${ }^{1} \mathrm{H}-\mathrm{NMR} \delta=2.98(\mathrm{dd}, J=13.6,8.8 \mathrm{~Hz}, 3 \mathrm{H}), 3.29$ (dd, $J=13.6,4.0 \mathrm{~Hz}, 1 \mathrm{H}), 3.85$ (dd, $J=9.2,8.0 \mathrm{~Hz}, 1 \mathrm{H}), 4.21$ (dd, $J=9.2,7.6 \mathrm{~Hz}, 1 \mathrm{H}), 4.60-4.68(\mathrm{~m}, 1 \mathrm{H}), 4.64\left(\mathrm{~A}\right.$ of $\mathrm{ABq}, J_{\mathrm{AB}}=$ $17.2 \mathrm{~Hz}, 1 \mathrm{H}), 4.69$ (B of ABq, $\left.J_{\mathrm{AB}}=17.2 \mathrm{~Hz}, 1 \mathrm{H}\right), 5.54(\mathrm{~s}, 1 \mathrm{H})$, 6.26-6.30 (m, 2H), 6.65 (dd, $J=2.4,1.6 \mathrm{~Hz}, 1 \mathrm{H}), 7.22-7.28(\mathrm{~m}$, $3 \mathrm{H}), 7.29-7.36(\mathrm{~m}, 2 \mathrm{H}) \mathrm{ppm} ;{ }^{13} \mathrm{C}-\mathrm{NMR} \delta=37.7,48.6,55.7,69.6$, 82.5 , 106.1, 110.3, 119.1, 122.3, 126.9, 128.7, 129.5, 136.2, 163.0 ppm; IR (neat) $\nu=3026,2925,2877,1719,1666,1547$, 1498, 1465, 1429, 1347, 1317, 1269, 1216, 1079, 1047, 973, 750, $693 \mathrm{~cm}^{-1}$; HRMS (ESI) calcd for $\mathrm{C}_{16} \mathrm{H}_{16} \mathrm{~N}_{2} \mathrm{O}_{2}+\mathrm{Na}, 291.1104$, found 291.1107.

(3S,6S)-3-Benzyl-6-methyl-2,3-dihydro-10bH-oxazolo[3,2-a] pyrrolo[2,1-c]pyrazin-5(6H)-one (10b). The reaction of methyl (S)-2-(2-formyl-1H-pyrrol-1-yl)propanoate (5b) (1.12 g, 6.19 $\mathrm{mmol})$ and L-phenylalaninol $(0.94 \mathrm{~g}, 6.19 \mathrm{mmol})$ in toluene (5 $\mathrm{mL}$ ) at room temperature for $2.5 \mathrm{~h}$ and then at $110{ }^{\circ} \mathrm{C}$ for $6 \mathrm{~h}$ produced $10 \mathrm{~b}$ (559 $\mathrm{mg}, 1.98 \mathrm{mmol}$ ) in $32 \%$ yield as light-yellow liquid after purification by $\mathrm{SiO}_{2}$ column chromatography.

Data for 10b. ${ }^{1} \mathrm{H}-\mathrm{NMR} \delta=1.65(\mathrm{~d}, J=7.2 \mathrm{~Hz}, 3 \mathrm{H}), 3.08(\mathrm{dd}, J$ $=13.6,8.0 \mathrm{~Hz}, 3 \mathrm{H}), 3.18(\mathrm{dd}, J=13.6,4.0 \mathrm{~Hz}, 1 \mathrm{H}), 3.88(\mathrm{dd}, J=$ $8.8,8.0 \mathrm{~Hz}, 1 \mathrm{H}), 4.24$ (dd, $J=8.8,8.0 \mathrm{~Hz}, 1 \mathrm{H}), 4.62$ (dddd, $J=$ 8.0, 8.0, 8.0, 4.0 Hz, 1H), 4.71 (q, $J=7.2 \mathrm{~Hz}, 1 \mathrm{H}), 5.41(\mathrm{~s}, 1 \mathrm{H})$, $6.22(\mathrm{ddd}, J=4.0,1.6,0.8 \mathrm{~Hz}, 1 \mathrm{H}), 6.26(\mathrm{dd}, J=4.0,2.8 \mathrm{~Hz}, 1 \mathrm{H})$, 6.65 (dd, $J=2.8,1.6 \mathrm{~Hz}, 1 \mathrm{H}), 7.20-7.28$ (m, 3H), 7.29-7.34 (m, 2H) ppm; ${ }^{13} \mathrm{C}-\mathrm{NMR} \delta=22.4,37.2,55.3,55.7,69.4,82.3,105.6$, 110.3, 118.1, 122.1, 127.0, 128.6, 129.8, 136.1, 166.7 ppm; IR (neat) $\nu=3027,2973,2920,2857,1714,1655,1566,1449,1422$, 1402, 1370, 1307, 1221, 1153, 1114, 1074, 1031, 973, 819, 751, $698 \mathrm{~cm}^{-1}$; HRMS (ESI) calcd for $\mathrm{C}_{17} \mathrm{H}_{18} \mathrm{~N}_{2} \mathrm{O}_{2}+\mathrm{Na}, 305.1260$, found 305.1264 .

(3S,6S)-3-Benzyl-6-isopropyl-2,3-dihydro-10bH-oxazolo[3,2-a] pyrrolo[2,1-c]pyrazin-5(6H)-one (10c). The reaction of methyl $(S)$-2-(2-formyl-1H-pyrrol-1-yl)-3-methylbutanoate (5c) (1.12 g, $5.36 \mathrm{mmol})$ and L-phenylalaninol $(0.81 \mathrm{~g}, 5.36 \mathrm{mmol})$ in toluene $(5 \mathrm{~mL})$ at room temperature for $2.5 \mathrm{~h}$ and then at $110{ }^{\circ} \mathrm{C}$ for $6 \mathrm{~h}$ produced 10c (682 mg, $2.20 \mathrm{mmol}$ ) in 41\% yield as light-yellow liquid after purification by $\mathrm{SiO}_{2}$ column chromatography.

Data for 10c. ${ }^{1} \mathrm{H}-\mathrm{NMR} \delta=0.89(\mathrm{~d}, J=6.8 \mathrm{~Hz}, 3 \mathrm{H}), 1.00(\mathrm{~d}, J=$ $6.4 \mathrm{~Hz}, 3 \mathrm{H}), 2.25(\mathrm{~m}, 1 \mathrm{H}), 2.92(\mathrm{dd}, J=13.2,9.2 \mathrm{~Hz}, 1 \mathrm{H}), 3.34$ (dd, $J=13.2,4.0 \mathrm{~Hz}, 1 \mathrm{H}), 3.85$ (dd, $J=8.8,7.2 \mathrm{~Hz}, 1 \mathrm{H}$ ), 4.17 (dd, $J=8.8,7.6 \mathrm{~Hz}, 1 \mathrm{H}), 4.44(\mathrm{~d}, J=4.8 \mathrm{~Hz}, 1 \mathrm{H}), 4.60$ (dddd, $J=9.2$, 7.6, 7.2, $4.0 \mathrm{~Hz}, 1 \mathrm{H}), 5.64(\mathrm{~s}, 1 \mathrm{H}), 6.24(\mathrm{dd}, J=3.6,2.4 \mathrm{~Hz}, 1 \mathrm{H})$, 
$6.26(\mathrm{ddd}, J=3.6,1.6,0.8 \mathrm{~Hz}, 1 \mathrm{H}), 6.62(\mathrm{dd}, J=2.4,1.6 \mathrm{~Hz}, 1 \mathrm{H})$, 7.22-7.28 (m, 3H), 7.29-7.34 (m, 2H) ppm; ${ }^{13} \mathrm{C}-\mathrm{NMR} \delta=18.1$, 19.3, 34.8, 37.7, 56.0, 65.9, 69.8, 82.7, 105.2, 109.4, 119.6, 123.8, 126.9, 128.6, 129.5, 136.4, 165.4 ppm; IR (neat) $\nu=3032,2958$, 2925, 2878, 1666, 1560, 1465, 1425, 1399, 1361, 1302, 1227, 1194, 1158, 1063, 1058, 1030, 967, 861, 756, $703 \mathrm{~cm}^{-1}$; HRMS (ESI) calcd for $\mathrm{C}_{19} \mathrm{H}_{22} \mathrm{~N}_{2} \mathrm{O}_{2}+\mathrm{Na}$, 333.1573, found 333.1576.

(3S,6S)-3-Benzyl-6-((S)-sec-butyl)-2,3-dihydro-10bH-oxazolo $[3,2-a]$ pyrrolo[2,1-c]pyrazin-5(6H)-one (10d). The reaction of methyl (2S,3S)-2-(2-formyl-1 $H$-pyrrol-1-yl)-3-methylpentanoate (5e) $(1.12 \mathrm{~g}, 5.02 \mathrm{mmol})$ and $\mathrm{L}$-phenylalaninol (0.76 g, 5.02 $\mathrm{mmol})$ in toluene $(5 \mathrm{~mL})$ at room temperature for $2.5 \mathrm{~h}$ and then at $110{ }^{\circ} \mathrm{C}$ for $6 \mathrm{~h}$ produced $10 \mathrm{~d}(505 \mathrm{mg}, 1.56 \mathrm{mmol})$ in $31 \%$ yield as light-yellow liquid after purification by $\mathrm{SiO}_{2}$ column chromatography.

Data for 10d. ${ }^{1} \mathrm{H}-\mathrm{NMR} \delta=0.91(\mathrm{~d}, J=6.8 \mathrm{~Hz}, 3 \mathrm{H}), 0.95(\mathrm{t}, J=$ $7.2 \mathrm{~Hz}, 3 \mathrm{H}), 1.00-1.14(\mathrm{~m}, 1 \mathrm{H}), 1.50-1.62(\mathrm{~m}, 1 \mathrm{H}), 1.92-2.04(\mathrm{~m}$, $1 \mathrm{H}), 2.93(\mathrm{dd}, J=13.2,8.8 \mathrm{~Hz}, 1 \mathrm{H}), 3.33(\mathrm{dd}, J=13.2,4.4 \mathrm{~Hz}, 1 \mathrm{H})$, $3.85(\mathrm{dd}, J=8.8,7.6 \mathrm{~Hz}, 1 \mathrm{H}), 4.17(\mathrm{dd}, J=8.8,7.6 \mathrm{~Hz}, 1 \mathrm{H}), 4.55(\mathrm{~d}, J$ $=5.2 \mathrm{~Hz}, 1 \mathrm{H}), 4.60$ (dddd, $J=8.8,7.6,7.6,4.4 \mathrm{~Hz}, 1 \mathrm{H}), 5.64(\mathrm{~s}, 1 \mathrm{H})$, $6.23-6.26(\mathrm{~m}, 2 \mathrm{H}), 6.62(\mathrm{dd}, J=2.8,1.6 \mathrm{~Hz}, 1 \mathrm{H}), 7.22-7.28(\mathrm{~m}, 3 \mathrm{H})$, 7.29-7.35 (m, 2H) ppm; ${ }^{13} \mathrm{C}-\mathrm{NMR} \delta=11.6,15.4,25.1,37.8,41.8$, 56.1, 64.7, 69.8, 82.7, 105.1, 109.6, 119.2, 123.8, 126.9, 128.6, 129.5, 136.4, 165.2 ppm; IR (neat) $\nu=3020,2958,2920,2872,1705,1655$, 1561, 1455, 1431, 1398, 1366, 1290, 1227, 1189, 1151, 1068, 1052, 1026, 978, 862, 735, $703 \mathrm{~cm}^{-1}$; HRMS (ESI) calcd for $\mathrm{C}_{20} \mathrm{H}_{24} \mathrm{~N}_{2} \mathrm{O}_{2}+$ $\mathrm{Na}, 347.1730$, found 347.1732 .

$(3 S, 6 S)-3,6-D i b e n z y l-2,3-d i h y d r o-10 b H$-oxazolo[3,2-a]pyrrolo [2,1-c]pyrazin-5(6H)-one (10e). The reaction of methyl $(S)-2-(2-$ formyl-1 $H$-pyrrol-1-yl)-3-phenylpropanoate (5f) (1.12 g, 4.36 $\mathrm{mmol})$ and L-phenylalaninol (0.66 g, $4.36 \mathrm{mmol})$ in toluene (5 $\mathrm{mL}$ ) at room temperature for $2.5 \mathrm{~h}$ and then at $110^{\circ} \mathrm{C}$ for $6 \mathrm{~h}$ produced 10e (969 mg, $2.70 \mathrm{mmol}$ ) in 62\% yield as light-yellow liquid after purification by $\mathrm{SiO}_{2}$ column chromatography.

Data for 10e. ${ }^{1} \mathrm{H}-\mathrm{NMR} \delta=2.41(\mathrm{dd}, J=13.2,10.4 \mathrm{~Hz}, 1 \mathrm{H}), 3.28$ (d of $\mathrm{A}$ of $\left.\mathrm{ABq}, J_{\mathrm{AB}}=13.6, J_{\mathrm{d}}=4.8 \mathrm{~Hz}, 1 \mathrm{H}\right), 3.32$ (d of $\mathrm{B}$ of $\mathrm{ABq}, J_{\mathrm{AB}}$ $\left.=13.6, J_{\mathrm{d}}=4.8 \mathrm{~Hz}, 1 \mathrm{H}\right), 3.44(\mathrm{dd}, J=13.2,4.4 \mathrm{~Hz}, 1 \mathrm{H}), 3.56(\mathrm{dd}$, $J=9.2,7.6 \mathrm{~Hz}, 1 \mathrm{H}), 3.99(\mathrm{dd}, J=9.2,7.6 \mathrm{~Hz}, 1 \mathrm{H}), 4.45$ (dddd, $J=$ 10.4, 7.6, 7.6, $4.4 \mathrm{~Hz}, 1 \mathrm{H}), 4.52(\mathrm{~s}, 1 \mathrm{H}), 4.95(\mathrm{t}, J=4.8 \mathrm{~Hz}, 1 \mathrm{H})$, $6.12(\mathrm{ddd}, J=4.0,1.6,0.8 \mathrm{~Hz}, 1 \mathrm{H}), 6.28(\mathrm{dd}, J=4.0,2.8 \mathrm{~Hz}, 1 \mathrm{H})$, $6.63(\mathrm{dd}, J=2.8,1.6 \mathrm{~Hz}, 1 \mathrm{H}), 6.71-6.76(\mathrm{~m}, 2 \mathrm{H}), 7.15-7.32(\mathrm{~m}$, $8 \mathrm{H}) \mathrm{ppm} ;{ }^{13} \mathrm{C}-\mathrm{NMR} \delta=37.6,41.8,55.7,60.6,70.1,81.4,104.9$, $110.4,117.9$, 123.7, 126.8, 127.5, 128.2, 128.7, 129.1, 129.7, 134.5, 136.5, $164.2 \mathrm{ppm}$; IR (neat) $\nu=3016,2915,2862,1655$, 1544, 1460, 1438, 1405, 1361, 1316, 1206, 1158, 1079, 1049, $1029,975,851,740,698 \mathrm{~cm}^{-1}$; HRMS (ESI) calcd for $\mathrm{C}_{23} \mathrm{H}_{22} \mathrm{~N}_{2} \mathrm{O}_{2}$ $+\mathrm{Na}, 381.1573$, found 381.1577 .

$(3 S, 6 S)-3-B e n z y l-6-p h e n e t h y l-2,3-d i h y d r o-10 b H$-oxazolo[3,2a]pyrrolo[2,1-c]pyrazin-5(6H)-one (10f). The reaction of methyl (S)-2-(2-formyl-1H-pyrrol-1-yl)-4-phenylbutanoate $(5 \mathrm{~g})$ (1.12 g, $4.13 \mathrm{mmol})$ and l-phenylalaninol $(0.63 \mathrm{~g}, 4.13 \mathrm{mmol})$ in toluene $(5 \mathrm{~mL})$ at room temperature for $2.5 \mathrm{~h}$ and then at $110{ }^{\circ} \mathrm{C}$ for $6 \mathrm{~h}$ produced $10 \mathrm{f}$ ( $877 \mathrm{mg}, 2.35 \mathrm{mmol}$ ) in $57 \%$ yield as light-yellow liquid after purification by $\mathrm{SiO}_{2}$ column chromatography.

Data for 10f. ${ }^{1} \mathrm{H}-\mathrm{NMR} \delta=2.19-2.36(\mathrm{~m}, 2 \mathrm{H}), 2.47-2.58(\mathrm{~m}$, $1 \mathrm{H}), 2.63-2.73(\mathrm{~m}, 1 \mathrm{H}), 2.99(\mathrm{dd}, J=13.6,8.4 \mathrm{~Hz}, 1 \mathrm{H}), 3.21$ (dd, $J$ $=13.6,4.0 \mathrm{~Hz}, 1 \mathrm{H}), 3.86(\mathrm{dd}, J=8.8,7.6 \mathrm{~Hz}, 1 \mathrm{H}), 4.21(\mathrm{dd}, J=$
8.8, 7.6 Hz, 1H), 4.62 (dddd, $J=8.4,7.6,7.6,4.0 \mathrm{~Hz}, 1 \mathrm{H}), 4.69(\mathrm{t}$, $J=6.0 \mathrm{~Hz}, 1 \mathrm{H}), 5.51(\mathrm{~s}, 1 \mathrm{H}), 6.26(\mathrm{ddd}, J=3.6,1.6,0.8 \mathrm{~Hz}, 1 \mathrm{H})$, $6.28(\mathrm{dd}, J=3.6,2.8 \mathrm{~Hz}, 1 \mathrm{H}), 6.65(\mathrm{dd}, J=2.8,1.6 \mathrm{~Hz}, 1 \mathrm{H}), 7.14-$ $7.19(\mathrm{~m}, 2 \mathrm{H}), 7.19-7.33(\mathrm{~m}, 8 \mathrm{H}) \mathrm{ppm} ;{ }^{13} \mathrm{C}-\mathrm{NMR} \delta=31.0,37.5$, 37.5 , 55.6, 59.5, 69.6, 82.4, 105.7, 110.2, 118.7, 122.9, 126.3, 127.0, 128.3, 128.6, 128.6, 129.6, 136.2, 140.0, 165.9 ppm; IR (neat) $\nu=3025,2964,2920,2862,1709,1666,1544,1443,1431$, 1338, 1325, 1211, 1074, 1026, 973, 772, $687 \mathrm{~cm}^{-1}$; HRMS (ESI) calcd for $\mathrm{C}_{24} \mathrm{H}_{24} \mathrm{~N}_{2} \mathrm{O}_{2}+\mathrm{Na}$, 395.1730, found 395.1733.

Methyl 2-((3S,6S)-3-benzyl-5-oxo-2,3,5,6-tetrahydro-10bHoxazolo[3,2-a]pyrrolo[2,1-c]pyrazin-6-yl)acetate $(\mathbf{1 0 g})$. The reaction of dimethyl $(S)$-2-(2-formyl-1H-pyrrol-1-yl)succinate $(\mathbf{5 h})$ $(1.12 \mathrm{~g}, 4.68 \mathrm{mmol})$ and L-phenylalaninol $(0.71 \mathrm{~g}, 4.69 \mathrm{mmol})$ in toluene $(5 \mathrm{~mL})$ at room temperature for $2.5 \mathrm{~h}$ and then at $110{ }^{\circ} \mathrm{C}$ for $6 \mathrm{~h}$ produced $10 \mathrm{~g}(223 \mathrm{mg}, 0.66 \mathrm{mmol})$ in 14\% yield as lightyellow liquid after purification by $\mathrm{SiO}_{2}$ column chromatography.

Data for 10g. ${ }^{1} \mathrm{H}-\mathrm{NMR} \delta=2.91(\mathrm{dd}, J=16.4,7.6 \mathrm{~Hz}, 1 \mathrm{H}), 3.02$ (dd, $J=13.6,8.8 \mathrm{~Hz}, 1 \mathrm{H}), 3.07$ (dd, $J=16.4,4.0 \mathrm{~Hz}, 1 \mathrm{H}), 3.29$ $(\mathrm{dd}, J=13.6,4.0 \mathrm{~Hz}, 1 \mathrm{H}), 3.69(\mathrm{~s}, 3 \mathrm{H}), 3.89(\mathrm{dd}, J=9.2,7.6 \mathrm{~Hz}$, $1 \mathrm{H}), 4.22$ (dd, $J=9.2,7.6 \mathrm{~Hz}, 1 \mathrm{H}$ ), 4.59 (dddd, $J=8.8,7.6,7.6$, $4.0 \mathrm{~Hz}, 1 \mathrm{H}), 5.05$ (dd, $J=7.6,4.0 \mathrm{~Hz}, 1 \mathrm{H}), 5.54$ (s, 1H), 6.22-6.27 $(\mathrm{m}, 2 \mathrm{H}), 6.70(\mathrm{dd}, J=2.4,1.6 \mathrm{~Hz}, 1 \mathrm{H}), 7.22-7.36$ (m, 5H) ppm; ${ }^{13} \mathrm{C}-\mathrm{NMR} \delta=37.2$, 39.7, 52.2, 55.8, 55.9, 69.7, 82.3, 105.8, 110.4, 118.9, 122.8, 127.0, 128.7, 129.6, 136.2, 164.4, 169.9 ppm; IR (neat) $\nu=3032,2947,2927,2867,1735,1666,1555,1455,1438$, 1442, 1400, 1365, 1317, 1221, 1168, 1084, 1026, 1029, 973, 898, 858, 830, 766, $703 \mathrm{~cm}^{-1}$; HRMS (ESI) calcd for $\mathrm{C}_{19} \mathrm{H}_{20} \mathrm{~N}_{2} \mathrm{O}_{4}+\mathrm{Na}$, 363.1315 , found 363.1319 .

(3S,6S)-3-Benzyl-6-(2-(methylthio)ethyl)-2,3-dihydro-10bHoxazolo[3,2-a]pyrrolo[2,1-c]pyrazin-5(6H)-one (10h). The reaction of methyl (S)-2-(2-formyl-1H-pyrrol-1-yl)-4-(methylthio) butanoate (5j) (1.12 g, $4.68 \mathrm{mmol})$ and L-phenylalaninol $(0.70 \mathrm{~g}, 4.65 \mathrm{mmol})$ in toluene $(5 \mathrm{~mL})$ at room temperature for $2.5 \mathrm{~h}$ and then at $110{ }^{\circ} \mathrm{C}$ for $6 \mathrm{~h}$ produced $10 \mathrm{~h}(353 \mathrm{mg}, 1.03$ $\mathrm{mmol}$ ) in $22 \%$ yield as light-yellow liquid after purification by $\mathrm{SiO}_{2}$ column chromatography.

Data for 10h. ${ }^{1} \mathrm{H}-\mathrm{NMR} \delta=2.07-2.17(\mathrm{~m}, 1 \mathrm{H}), 2.11(\mathrm{~s}, 3 \mathrm{H})$, 2.20-2.31 (m, 1H), 2.32-2.40 (m, 1H), 2.48-2.57 (m, 1H), 3.04 (dd, $J=13.6,8.4 \mathrm{~Hz}, 1 \mathrm{H}), 3.22(\mathrm{dd}, J=13.6,4.0 \mathrm{~Hz}, 1 \mathrm{H}), 3.88$ $(\mathrm{dd}, J=9.2,7.6 \mathrm{~Hz}, 1 \mathrm{H}), 4.21(\mathrm{dd}, J=9.2,7.6 \mathrm{~Hz}, 1 \mathrm{H}), 4.61$ (dddd, $J=8.4,7.6,7.6,4.0 \mathrm{~Hz}, 1 \mathrm{H}), 4.79(\mathrm{dd}, J=7.2,5.6 \mathrm{~Hz}, 1 \mathrm{H})$, 5.49 (s, 1H), 6.23-6.27 (m, 2H), 6.67 (dd, $J=2.4,2.0 \mathrm{~Hz}, 1 \mathrm{H})$, 7.20-7.35 (m, 5H) ppm; ${ }^{13} \mathrm{C}-\mathrm{NMR} \delta=15.2,29.3$, 35.0, 37.3, 55.6, 58.6, 69.5, 82.4, 105.7, 110.1, 118.9, 122.9, 127.0, 128.6, 129.6, 136.2, 165.7 ppm; IR (neat) $\nu=3015,2915,2846,1709,1655$, 1570, 1539, 1478, 1455, 1426, 1347, 1323, 1302, 1211, 1200, 1147, 1075, 1032, 977, 854, 818, 739, $701 \mathrm{~cm}^{-1}$; HRMS (ESI) calcd for $\mathrm{C}_{19} \mathrm{H}_{22} \mathrm{~N}_{2} \mathrm{O}_{2} \mathrm{~S}+\mathrm{Na}$, 365.1294, found 365.1296.

\section{Conclusions}

We demonstrated a practically efficient transformation method of D-ribose as sustainable reducing sugar with various $\alpha$-amino acids into pyrralines 5 as platform chemicals. Up to $300 \%$ yield increasement of pyrralines 5 (32-63\% yield) were realized by one-pot pressurized conversion of D-ribose with various $\alpha$ - 
amino esters at $2.5 \mathrm{~atm}$ and $80{ }^{\circ} \mathrm{C}$. The pyrrole-based platform chemicals 5 containing formyl and ester groups as linchpin units were further cyclized to form the piperazin-2-one scaffold as the second pharmacophore. Reductive amination of the formyl group with benzylamine, followed by intramolecular amination with the ester group provided pyrrolo-piperazinones 6 in reasonable yields. 1,2-Ethanediamine reacted with the formyl group of pyrralines $\mathbf{5}$ by double amination, and the resulting secondary amine underwent subsequent amination with the ester group to produce pyrrolo-piperazinones 7 with an imidazolidine ring as the third structural unit in high yields. Likewise, 2 -amino alcohols derived from natural $\alpha$-amino acids, alanine, valine, and phenylalanine, respectively reacted with the formyl group of pyrralines 5 to give intermediate oxazolidines, which underwent further cyclization with the ester group to produce triply fused heterocycles 8-10 of pyrrole, piperazin-2one, and oxazolidine in acceptable yields. Pyrrolopiperazinones $\mathbf{8 h}$ and $\mathbf{1 0 g}$ with an oxazolidine motif exhibited significant anti-inflammation activities with high cell viability. The practical synthetic method of platform chemicals 5 from sustainable biomass would open a paved road to the discovery of new therapeutic agents and value-added functional materials.

\section{Author contributions}

S. Cho: synthesis (lead); L. Gu: synthesis (equal); I. J. In: synthesis (supporting); B. Wu: investigation (equal), synthesis (supporting); T. Lee: bioassays (lead); H. Kim: bioassay (equal), funding acquisition (equal); S. Koo: project administration (lead), funding acquisition (lead), investigation (lead), formal analysis (lead), data curation (lead), writing manuscript (lead).

\section{Conflicts of interest}

There are no conflicts to declare.

\section{Acknowledgements}

This study was supported by basic science research program and international cooperation program through the National Research Foundation of Korea (NRF, 2020R1A6A1A03038817 and 2017K2A9A2A06016784) and by the Ministry of Science and ICT (2020R1A2C1010724), and partly by the GRRC Program of Gyeonggi province [GRRC-KyungHee2018(B01)], Republic of Korea. This paper is dedicated to my dear Professor Lanny S. Liebeskind.

\section{Notes and references}

1 V. Bhardwaj, D. Gumber, V. Abbot, S. Dhiman and P. Sharma, RSC Adv., 2015, 5, 15233-15266.

2 A. Domagala, T. Jarosz and M. Lapkowski, Eur. J. Med. Chem., 2015, 100, 176-187.

3 D. O'Hagan, Nat. Prod. Rep., 2000, 17, 435-446.

4 S. Thirumalairajan, B. M. Pearce and A. Thompson, Chem. Commun., 2010, 46, 1797-1812.
5 H. Fan, J. Peng, M. T. Hamann and J.-F. Hu, Chem. Rev., 2008, 108, 264-287.

6 S. S. Gholap, Eur. J. Med. Chem., 2016, 110, 13-31.

7 H. Li, H. Guo, Z. Fang, T. M. Aida and R. L. Smith Jr, Green Chem., 2020, 22, 582-611.

8 H. Hoffmann and T. Lindel, Synthesis, 2003, 1753-1783.

9 R. Khajuria, S. Dhamb and K. K. Kapoor, RSC Adv., 2016, 6, 37039-37066.

10 C. Paal, Ber. Dtsch. Chem. Ges., 1884, 17, 2756-2767.

11 L. Knorr, Ber. Dtsch. Chem. Ges., 1884, 17, 2863-2870.

12 C. Paal, Ber. Dtsch. Chem. Ges., 1885, 18, 367-371.

13 A. Hantzsch, Ber. Dtsch. Chem. Ges., 1890, 23, 1474-1476.

14 F. Feist, Ber. Dtsch. Chem. Ges., 1902, 35, 1537-1544.

15 N. Clauson-Kaas, F. Limborg and J. Fakstorp, Acta Chem. Scand., 1948, 2, 109-115.

16 A. Kornienko and J. J. La Clair, Nat. Prod. Rep., 2017, 34, 1051-1060.

17 Y. Ju, D. Miao, R. Yu and S. Koo, Org. Biomol. Chem., 2015, 13, 2588-2599.

18 X. Jiang, H. Jin, T. Wang, H. Yoo and S. Koo, Synthesis, 2019, 51, 3259-3268.

19 H. Jin, X. Jiang, H. Yoo, T. Wang, C. G. Sung, U. Choi, C.-R. Lee, H. Yu and S. Koo, ChemistrySelect, 2020, 5, 12421-12424.

20 R. U. Braun, K. Zeitler and T. J. J. Müller, Org. Lett., 2001, 3, 3297-3300.

21 G. Minetto, L. F. Raveglia and M. Taddei, Org. Lett., 2004, 6, 389-392.

22 B. Wang, Y. Gu, C. Luo, T. Yang, L. Yang and J. Suo, Tetrahedron Lett., 2004, 45, 3417-3419.

23 M. Leonardi, V. Estévez, M. Villacampa and J. C. Menéndez, Synthesis, 2018, 50, 816-828.

24 M. W. Roomi and S. F. MacDonald, Can. J. Chem., 1970, 48, 1689-1697.

25 V. Estévez, M. Villacampa and J. C. Menéndez, Chem. Soc. Rev., 2010, 39, 4402-4421.

26 V. Estévez, M. Villacampa and J. C. Menéndez, Chem. Soc. Rev., 2014, 43, 4633-4657.

27 Y. Fang, D. Leysen and H. C. J. Ottenheijm, Synth. Commun., 1995, 25, 1857-1861.

28 B. S. Gourlay, P. P. Molesworth, J. H. Ryan and J. A. Smith, Tetrahedron Lett., 2006, 47, 799-801.

29 B. Zuo, J. Chen, M. Liua, J. Ding, H. Wu and W. Su, J. Chem. Res., 2009, 14-16.

30 D. Bandyopadhyay, S. Mukherjee and B. K. Banik, Molecules, 2010, 15, 2520-2525.

31 G. Balme, Angew. Chem., Int. Ed., 2004, 43, 6238-6241.

32 S. Michlik and R. Kempe, Nat. Chem., 2013, 5, 140-144.

33 Y. Yamamoto, H. Hayashi, T. Saigoku and H. Nishiyama, J. Am. Chem. Soc., 2005, 127, 10804-10805.

34 A. A. Rosatella, S. P. Simeonov, R. F. M. Frade and C. A. M. Afonso, Green Chem., 2011, 13, 754-793.

35 J. B. Binder and R. T. Raines, J. Am. Chem. Soc., 2009, 131, 1979-1985.

36 X. Tong, Y. Ma and Y. Li, Appl. Catal., A, 2010, 385, 1-13.

37 S. I. F. S. Martins, W. M. F. Jongen and M. A. J. S. von Boekel, Trends Food Sci. Technol., 2001, 11, 364-373. 
38 F. Hayase, R. H. Nagaraj, S. Miyata, F. G. Njoroge and V. M. Monnier, J. Biol. Chem., 1989, 263, 3758-3764.

39 G. V. Mokrov, A. M. Likhosherstov, V. S. Troitskaya and T. A. Gudasheva, Russ. J. Org. Chem., 2009, 45, 1829-1833.

40 G. V. Mokrov, A. M. Likhosherstov, V. P. Lezina, T. A. Gudasheva, I. S. Bushmarinov and M. Yu. Antipin, Russ. Chem. Bull., 2010, 59, 1254-1266.

41 G. V. Mokrov, A. M. Likhosherstov, V. P. Lezina, T. A. Gudasheva, I. S. Bushmarinov and M. Yu. Antipin, Russ. Chem. Bull., 2011, 60, 1694-1702.

42 A. S. Demir, N. T. Subasia and E. Sahin, Tetrahedron: Asymmetry, 2006, 17, 2625-2631.

43 J. M. Wood, D. P. Fukert and M. A. Bimble, Nat. Prod. Rep., 2019, 36, 289-306.

44 H. Kato and M. Fujimaki, Agric. Biol. Chem., 1970, 34, 10711077.

45 N. D. Adhikary, S. Kwon, W.-J. Chung and S. Koo, J. Org. Chem., 2015, 80, 7693-7701.

46 A. M. Valdivielso, P. Ventosa-Andrés, M. T. García-López, R. Herranz and M. Gutiérrez-Rodríguez, Eur. J. Org. Chem., 2013, 155-161.

47 C. De Risi, M. Pelà, G. P. Pollini, C. Trapella and V. Zanirato, Tetrahedron: Asymmetry, 2010, 21, 255-274.

48 H. Zhang, T. Cravillion, N.-K. Lim, Q. Tian, D. Beaudry, J. L. Defreese, A. Fettes, P. James, D. Linder and S. Malhotra, et. al., Org. Process Res. Dev., 2018, 22, 978-990.

49 C. Sandoval, N.-K. Lim and H. Zhang, Org. Lett., 2018, 20, 1252-1255.

50 T. Yamashita, E. Tsuru, E. Banjyo, M. Doe, K. Shibata, M. Yasuda and M. Gemba, Chem. Pharm. Bull., 1997, 45, 1940-1944.
51 J. Sanchez-Cespedes, C. L. Moyer, L. R. Whitby, D. L. Boger and G. R. Nemerow, Antiviral Res., 2014, 108, 65-73.

52 P. Z. Aviv, M. Shubely, Y. Moskovits, O. Viskind, A. Albeck, D. Vertommen, S. Ruthstein, M. Shokhen and A. Gruzman, ChemistrySelect, 2016, 1, 4658-4667.

53 H. J. Kim, W. Y. Kwak, J. P. Min, J. Y. Lee, T. H. Yoon, H. D. Kim, C. Y. Shin, M. K. Kim, S. H. Choi, H. S. Kim, et al., Bioorg. Med. Chem. Lett., 2011, 21, 3809-3812.

54 Q. Liu, Q. Shi, D. Marcoux, D. G. Batt, L. Cornelius, L.-Y. Qin, Z. Ruan, J. Neels, M. Beaudoin-Bertrand, A. S. Srivastava, et al., J. Med. Chem., 2017, 60, 5193-5208.

55 W.-Q. Zuo, R. Hu, W.-L. Wang, Y.-X. Zhu, Y. Xu, L.-T. Yu, Z.-H. Liu and N.-Y. Wang, Bioorg. Chem., 2020, 105, 104344.

56 M. D'Ambrosio, A. Guerriero, C. Debitus, O. Ribes, J. Pusset, S. Leroy and F. Pietra, J. Chem. Soc., Chem. Commun., 1993, 1305-1306.

57 T. W. Hong, D. R. Jímenez and T. F. Molinski, J. Nat. Prod., 1998, 61, 158-161.

58 F. Cafieri, E. Fattorusso, A. Mangoni and O. TaglialatelaScafati, Tetrahedron Lett., 1995, 36, 7893-7896.

59 I. Mancini, G. Guella, P. Amade, C. Roussakis and F. Pietra, Tetrahedron Lett., 1997, 38, 6271-6274.

60 M. Tsuda, T. Yasuda, E. Fukushi, J. Kawabata, M. Sekiguchi, J. Fromont and J. Kobayashi, Org. Lett., 2006, 8, 4235-4238.

61 T. Henle and A. Bachmann, Z. Lebensm.-Unters. Forsch., 1996, 202, 72-74.

62 T. Niwa, J. Chromatogr. B: Biomed. Sci. Appl., 1999, 731, 2336.

63 T. Mosmann, J. Immunol. Methods, 1983, 65, 55-63.

64 M. J. Moorcroft, J. Davis and R. G. Compton, Talanta, 2001, 54, 785-803. 